Research Article

\title{
A Step towards Integrating CMORPH Precipitation Estimation with Rain Gauge Measurements
}

\author{
Augusto José Pereira Filho ${ }^{D},{ }^{1}$ Felipe Vemado $\left(D,{ }^{1}\right.$ Guilherme Vemado ${ }^{(D)}{ }^{1}$ \\ Fábio Augusto Gomes Vieira Reis $(\mathbb{D}),{ }^{2}$ Lucilia do Carmo Giordano (D), \\ Rodrigo Irineu Cerri $\left(\mathbb{D},{ }^{2}\right.$ Cláudia Cristina dos Santos $\mathbb{D}^{3},{ }^{3}$ Eymar Silva Sampaio Lopes $\mathbb{D}^{3},{ }^{3}$ \\ Marcelo Fischer Gramani $\left(\mathbb{D},{ }^{4}\right.$ Agostinho Tadashi Ogura ${ }^{\mathbb{D}},{ }^{4}$ José Eduardo Zaine $\mathbb{D}^{2},{ }^{2}$ \\ Leandro Eugenio da Silva Cerri ${ }^{D},{ }^{2}$ Oswaldo Augusto Filho ${ }^{(D},{ }^{5}$ \\ Fernando Mazo D'Affonseca ${ }^{(D)}{ }^{6}$ and Cláudio dos Santos Amaral (iD ${ }^{7}$
}

${ }^{1}$ Departamento de Ciências Atmosféricas, Instituto de Astronomia, Geofísica e Ciências Atmosféricas, Universidade de São Paulo, São Paulo, Brazil

${ }^{2}$ Instituto de Geociências e Ciências Exatas, Universidade Estadual Paulista, Rio Claro, São Paulo, Brazil

${ }^{3}$ Instituto Nacional de Pesquisas Espaciais, São José dos Campos, São Paulo, Brazil

${ }^{4}$ Instituto de Pesquisas Tecnológicas, São Paulo, Brazil

${ }^{5}$ Escola de Engenharia de São Carlos, Universidade de São Paulo, São Paulo, Brazil

${ }^{6}$ Eberhard Karls Universität Tübingen, Tübingen, Germany

${ }^{7}$ Petrobras Research and Development Center, Rio de Janeiro, Brazil

Correspondence should be addressed to Augusto José Pereira Filho; augusto.pereira@iag.usp.br

Received 1 August 2018; Accepted 5 November 2018; Published 17 December 2018

Academic Editor: Harry D. Kambezidis

Copyright (C) 2018 Augusto José Pereira Filho et al. This is an open access article distributed under the Creative Commons Attribution License, which permits unrestricted use, distribution, and reproduction in any medium, provided the original work is properly cited.

\begin{abstract}
Accurate daily rainfall estimation is required in several applications such as in hydrology, hydrometeorology, water resources management, geomorphology, civil protection, and agriculture, among others. CMORPH daily rainfall estimations were integrated with rain gauge measurements in Brazil between 2000 and 2015, in order to reduce daily rainfall estimation errors by means of the statistical objective analysis scheme (SOAS). Early comparisons indicated high discrepancies between daily rain gauge rainfall measurements and respective CMORPH areal rainfall accumulation estimates that tended to be reduced with accumulation time span (e.g., yearly accumulation). Current results show CMORPH systematically underestimates daily rainfall accumulation along the coastal areas. The normalized error variance (NEXERVA) is higher in sparsely gauged areas at Brazilian North and Central-West regions. Monthly areal rainfall averages and standard deviation were obtained for eleven Brazilian watersheds. While an overall negative tendency $\left(3 \mathrm{~mm} \cdot \mathrm{h}^{-1}\right)$ was estimated, the Amazon watershed presented a long-term positive tendency. Monthly areal mean precipitation and respective spatial standard deviation closely follow a power-law relationship for data-rich watersheds, i.e., with denser rain gauge networks. Daily SOAS rainfall accumulation was also used to calculate the spatial distribution of frequencies of 3-day rainfall episodes greater than $100 \mathrm{~mm}$. Frequencies greater than 3\% were identified downwind of the Peruvian Andes, the Bolivian Amazon Basin, and the La Plata Basin, as well as along the Brazilian coast, where landslides are recurrently triggered by precipitation.
\end{abstract}

\section{Introduction}

In recent years, many new environmental satellites have been deployed to monitor Earth from space [1] at an increasing spatial-temporal resolution. Concomitantly, several techniques for rainfall estimation [2] were developed and are being used such as the Tropical Rainfall Measuring Mission (TRMM) Multisatellite Precipitation Analysis 
(TMPA), Climate Prediction Center morphing technique (CMORPH), the Precipitation Estimation from Remotely Sensed Information Using Artificial Neural Networks (PERSIANN), Global Precipitation Climatology Project (GPCP), Global Satellite Mapping of Precipitation (GSMAP), Naval Research Laboratory (NRL), and others that combine infrared (IR) and microwave (MW) measurement sensors to estimate rainfall rates [2]. All techniques are currently evaluated and verified against ground-based measurements (e.g., rain gauges) and estimates (e.g., weather radar) over oceanic and continental areas. Shanhu et al. [3] compared TMPA and CMORPH precipitation estimates with rain gauge measurements over watersheds. Kumar et al. [4] evaluated topographic effects on daily rainfall estimates from TRMM and CMORPH and indicated the latter yielded lower rainfall rates. TRMM high rainfall rate measurements have been compared to the respective rain gauge measurements over China in [5]. Skok et al. [6] compared TRMM, CMORPH, and four rain gauge networks and found negative biases over land and positive biases over the ocean. Salio et al. [7] compared TRMM and CMORPH over South America. Zhang et al. [8] compared CMORPH areal precipitation estimates with respective areal precipitation measurements with weather radars and rain gauges during winter and summer. Zubieta et al. [9] used TMPA, CMORPH, and PERSIANN precipitation estimates for rain-runoff modeling in Amazon Basin, while Buarque et al. [10] compared rain gauge measurements with TRMM and CMORPH in Amazon. Habib et al. [11] compared weather radar estimates, rain gauge measurements, and CMORPH estimates of rainfall in Southern USA. Luo et al. [12] compared CMORPH and more than 30,000 rain gauges in China for the year 2005, and Shen et al. [13] compared them during spring and summer from 2008 to 2010. Sohn et al. [14] compared the performance by diurnal cycle and season of TRMM, TMPA, CMORPH, PERSIANN, and NRL with rain gauges in Korea and observed that TMPA provided the best estimate in real time. Stampoulis and Anagnoustou [15] evaluated TRMM and CMORPH with rain gauges over Europe and evaluated the estimates by season and topographic effects. Tian and Peters-Lidard and Maggioni et al. [16, 17] discussed global uncertainties on satellite precipitation estimates obtained by TRMM, CMORPH, GSMAP, PERSIANN, and NRL. Tobin and Bennett [18] compared TRMM and CMORPH with rain gauges for hydrologic modeling validation. Vera and Terra [19] compared CMORPH precipitation estimates with rain gauge measurements in Uruguay. Filho et al. [20] compared daily, monthly, seasonal, and annual CMORPH precipitation estimates with respective rain gauge measurements in South America and showed that the CMORPH estimates are better correlated with rain gauges with increasing accumulation.

Daily precipitation is an important variable for many applications over watersheds, which are units of evaluation of the water resources as specified by the 1997 Brazilian Water Bill. The management of each watershed requires hydrometeorologic measurements of precipitation, streamflow, evapotranspiration, infiltration, and groundwater storage and transmissivity. Most Brazilian watersheds have very long records of precipitation and streamflow on a daily basis. The total number of rain gauges in record in Brazil is 11,427, leading to an average distance between gauges close to $50 \mathrm{~km}$ (Table 1). However, this average considerably changes among regions, varying from $17 \mathrm{~km}$ in the Southeast to $99 \mathrm{~km}$ in the North. The present study integrates CMORPH daily precipitation estimates with daily rainfall measurements of 7,759 rain gauges selected during 2000 to 2015 .

The Amazon Basin contains nearly $70 \%$ of the total freshwater, but it is the Brazilian region with the lowest density of rain gauges per square kilometer (Figure 1). The Amazon Basin is a new frontier for new hydropower generation projects $[21,22]$, and so better precipitation measurements are required for water management. There are other demands for precipitation information on time and space scales less than 1 hour and few square kilometers, respectively, that will not be met without the integration of the rain gauge network with satellite rainfall estimation [23]. As previously shown, a variety of satellite rainfall estimates are currently available. In this research work, the CMORPH method integrated with the rain gauge measurements of daily rainfall accumulation is used. The integration is performed with the statistical objective analysis scheme (SOAS), originally developed in [24] to integrate weather radar precipitation estimates with rain gauge measurements.

The CMORPH rainfall accumulation has spatial and temporal resolutions of $\sim 8 \mathrm{~km}$ and $30 \mathrm{~min}$, respectively. Daily rain gauge precipitation accumulation measurements ending at 1000 UTC (Coordinated Universal Time) and respective CMORPH precipitation estimates are used in the integration process with the SOAS. Once the daily rainfall analysis is achieved, it can be disaggregated into $30 \mathrm{~min}$ accumulation. This approach is very useful in applications that demand much higher spatial-temporal resolution because the density of rainfall estimates can be augmented by at least threefold with a homogeneous spatial distribution. A network of 190 weather radars or 135,000 rain gauges would be necessary just to blank the Brazilian territory alone with a similar density, meaning an investment more than US\$ 1 billion in each of these measurement systems.

All the previous works were related to comparisons and the use of different satellite precipitation estimation techniques. Here, a first step towards merging CMORPH and rain gauges at a very high temporal resolution over Brazil is introduced. The statistics were obtained for isotropic conditions for the average daily precipitation estimate with CMORPH over the period between 2000 and 2015. Other SOAS refinements by region, season, and precipitation type are not investigated and may be assessed by further research. Herein, the main objective is to diagnose the Brazilian rain gauge network based on consistent statistics and to obtain a first approach integration with rain gauges to estimate accuracies, errors, and regional and local effects such as topography. Section 2 describes the revised CMORPH datasets [25], the rain gauge network and selection criteria, a brief description of the SOAS [24] with the statistics, and spatial error analysis. 
TABLE 1: Main characteristics of the rain gauge network in Brazil by region, state, their respective area $\left(\mathrm{km}^{2}\right)$, total number of gauges (total \#), total number of gauges after filtering missing data (\# filtered), average distance $(\mathrm{km})$ between gauges, and percentage of the rain gauges after filtering.

\begin{tabular}{|c|c|c|c|c|c|}
\hline & $\begin{array}{l}\text { Area } \\
\left(\mathrm{km}^{2}\right)\end{array}$ & $\begin{array}{c}\text { Total } \\
\#\end{array}$ & $\begin{array}{c}\# \\
\text { filtered }\end{array}$ & $\begin{array}{l}\text { Distance } \\
(\mathrm{km})\end{array}$ & $\begin{array}{c}\% \text { total } \\
\#\end{array}$ \\
\hline \multicolumn{6}{|l|}{ North } \\
\hline Acre & 163,648 & 20 & 6 & 165.2 & 30.0 \\
\hline Amapa & 140,480 & 105 & 70 & 44.8 & 66.7 \\
\hline Amazonas & $1,538,110$ & 199 & 155 & 99.6 & 77.9 \\
\hline Pará & $1,230,080$ & 123 & 94 & 114.4 & 76.4 \\
\hline Rondônia & 237,760 & 24 & 12 & 140.8 & 50.0 \\
\hline Roraima & 221,056 & 54 & 38 & 76.3 & 70.4 \\
\hline \multirow[t]{2}{*}{ Tocatins } & 276,416 & 181 & 96 & 53.7 & 53.0 \\
\hline & $3,807,550$ & 706 & 471 & 99.2 & 60.6 \\
\hline \multicolumn{6}{|l|}{ Northeast } \\
\hline Alagoas & 27,768 & 76 & 36 & 27.8 & 47.4 \\
\hline Bahia & 568,256 & 508 & 385 & 38.4 & 75.8 \\
\hline Ceará & 146,688 & 1.002 & 694 & 14.5 & 69.3 \\
\hline Maranhão & 327,680 & 290 & 147 & 47.2 & 50.7 \\
\hline Paraíba & 56,512 & 56 & 28 & 44.9 & 50.0 \\
\hline Pernanbuco & 97,664 & 122 & 66 & 38.5 & 54.1 \\
\hline \multirow{4}{*}{$\begin{array}{l}\text { Piauí } \\
\text { Rio Grande do } \\
\text { Norte } \\
\text { Sergipe }\end{array}$} & 249,088 & 356 & 255 & 31.3 & 71.6 \\
\hline & 52,608 & 34 & 22 & 48.9 & 64.7 \\
\hline & 22,016 & 38 & 24 & 30.3 & 63.2 \\
\hline & $1,548,280$ & 2.482 & 1.657 & 35.8 & 60.7 \\
\hline \multirow{5}{*}{$\begin{array}{l}\text { Central-West } \\
\text { Goiás } \\
\text { Mato Grosso } \\
\text { Mato Grosso } \\
\text { do Sul }\end{array}$} & & & & & \\
\hline & 347,648 & 345 & 254 & 37.0 & 73.6 \\
\hline & 910,336 & 191 & 139 & 80.9 & 72.8 \\
\hline & 373,696 & 199 & 121 & 55.6 & 60.8 \\
\hline & $1,631,680$ & 735 & 514 & 57.8 & 69.1 \\
\hline \multicolumn{6}{|l|}{ Southeast } \\
\hline Espírito Santo & 47,936 & 268 & 172 & 16.7 & 64.2 \\
\hline Minas Gerais & 606,464 & 1.903 & 1.201 & 22.5 & 63.1 \\
\hline Rio de Janeiro & 46,272 & 205 & 159 & 17.1 & 77.6 \\
\hline \multirow[t]{2}{*}{ São Paulo } & 263,296 & 2.674 & 1.670 & 12.6 & 62.5 \\
\hline & 963,968 & 5.050 & 3.202 & 17.2 & 66.8 \\
\hline \multicolumn{6}{|l|}{ South } \\
\hline \multirow{4}{*}{$\begin{array}{l}\text { Paraná } \\
\text { Rio Grande } \\
\text { do Sul } \\
\text { Santa Catarina }\end{array}$} & 215,232 & 1.234 & 1.036 & 14.4 & 84.0 \\
\hline & 318,016 & 768 & 528 & 24.5 & 68.8 \\
\hline & 105,792 & 431 & 336 & 17.7 & 78.0 \\
\hline & 639,040 & 2.433 & 1.900 & 18.9 & 76.9 \\
\hline Brazil & $8,596,320$ & 11.427 & 7.759 & 49.4 & 64.7 \\
\hline
\end{tabular}

Section 3 shows results of the precipitation integration, difference fields, and average performance by state, major watersheds, and the overall analysis for entire Brazil. Concluding remarks are given in Section 4.

\section{Materials and Methods}

2.1. Precipitation Datasets. High spatiotemporal resolution quantitative precipitation estimation (QPE) and quantitative precipitation forecast $(\mathrm{QPF})$ are very important in many applications such as civil protection, water management, and numerical weather prediction, assimilation, and verification, among many others, especially where surface

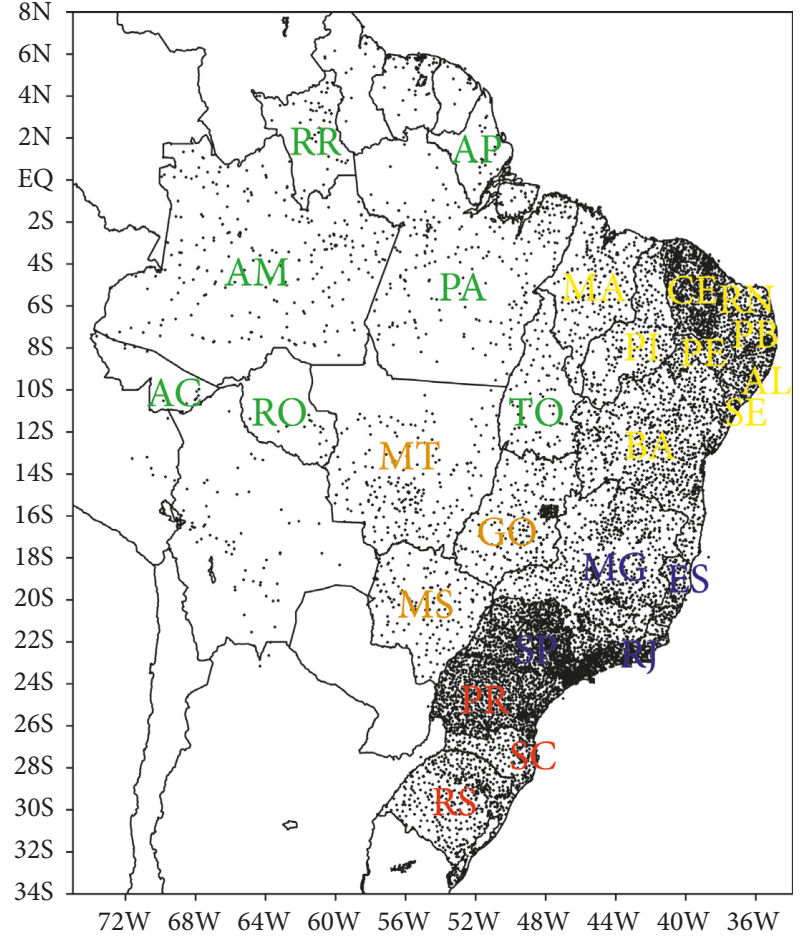

Figure 1: Spatial distribution of rain gauges (dots) in Brazil by regions (colors): North (green), Northeast (yellow), Central-West (brown), Southeast (blue), and South (red), and by states (twoletter code): AM (Amazonas), PA (Pará), TO (Tocantins), RO (Rondônia), AC (Acre), RR (Roraima), AP (Amapá), MA (Maranhão), PI (Piauí), CE (Ceará), RN (Rio Grande do Norte), PB (Paraíba), PE (Pernambuco), AL (Alagoas), SE (Sergipe), MT (Mato Grosso), MS (Mato Grosso do Sul), GO (Goiás), MG (Minas Gerais), ES (Espírito Santo), RJ (Rio de Janeiro), SP (São Paulo), PR (Paraná), SC (Santa Catarina), and RS (Rio Grande do Sul). Latitudes, longitudes, and geographic boundaries are indicated. Rain gauges in Bolivia and Peru used in this study to blank Amazon Basin are also indicated.

measurements are sparse or not available (deserts, oceans, and remote continental areas). In general, global numerical models have poor performance due to unspecified diurnal cycle forcing in these regions [26] as well as long-term ground water storage variation [27]. Many important regions around the planet Earth lack surface weather station networks, for instance, over oceans, where there are virtually none. In many locations, however, the weather report is made available every $6 \mathrm{hr}$ to $24 \mathrm{hr}$. Therefore, highresolution precipitation estimation by means of remote sensing is essential, in particular for South America and Africa. The critical element for hydrologic simulations or forecasts is the precipitation field at past, present, and future time intervals. Consequently, it is appropriate to begin the development of a hydrometeorologic forecast system with an evaluation of the precipitation field.

2.2. CMORPH Dataset. The improvement of the precipitation estimate has been developed internationally through the inclusion of information from rain gauges, 
weather radars, and satellite networks with advanced integration techniques. Satellite infrared data are available worldwide at any time every $15 \mathrm{~min}$ and higher in other regions such as the United States of America and Japan. However, the infrared estimates the brightness temperature of cloud tops, and it does not always match well with surface rainfall rates. Often, cold cloud tops within convective systems can be larger than the surface rainfall area. Sometimes, no rain exists where cooler cirrus and stratus are present. Furthermore, nonprecipitating clouds can be easily confused with precipitating clouds in the infrared channel, and rainfall can be associated with warm shallower clouds in coastal areas where topographic effects are important, like in the Brazilian Coast and East Pacific at the intertropical convergence zone (ITCZ).

The low-frequency signal from the passive microwave satellite measures the thermal emission of raindrops as upward high frequencies or emerging scattered radiation from ice particles within clouds and their tops. The PW sensors are installed in polar orbiting satellites that sweep the globe every 3 hours. On the contrary, infrared sensors onboard geostationary satellites can scan an entire hemisphere in 15 minutes or less. Each sensor has limiting factors, so they are combined to obtain the best precipitation estimation possible, such as the scheme proposed in [28] that combines PW and GOES IR measurements to weather radar data.

Miller et al. [29] developed another technique in which the estimation derived from the microwave sensors is regressed with IR brightness temperature locally to estimate precipitation when microwave data were unavailable. Furthermore, Turk et al. [30] developed a scheme to determine the brightness temperature limit for precipitation by comparing the brightness temperature distribution with estimates of microwave precipitation at the same point. This relationship was used to estimate rainfall from IR data where no microwave data were available.

The scheme in [31] uses microwave data to calibrate IR data. These techniques estimate precipitation directly from the IR data through empirical relationships between precipitation rate and cloud top temperatures. One of the several sources of errors of these methods is the uncertainty in brightness temperatures and precipitation ratios, especially so over the extratropics but summer when stratiform precipitation is dominant.

The CMORPH $[25,32]$ produces rainfall estimates globally at very high spatial $(\sim 8 \mathrm{~km})$ and temporal $(30 \mathrm{~min})$ resolutions. Rainfall rates are obtained from the low-orbit passive microwave satellites and advected by winds derived from the respective infrared measurements of geostationary satellites. The passive microwave sensors are on-board DMSP 13, 14, and 15 (SSM/I), NOAA 15, 16, 17, and 18 (AMSU-B), and AMSR-E and the TMI on board of NASA's Aqua and TRMM satellites.

Rainfall estimates are derived from the algorithm developed in [33] for the SSM/I sensor, in [34] for AMSU-B, and in [35] for the TMI. The technique is not a precipitation estimation algorithm in itself but a means by which microwave rainfall algorithms can be combined. It is flexible so that any rainfall rate estimate from any passive microwave measurement can be included. The spatial resolution varies between $8 \mathrm{~km}$ at the equator and $15 \mathrm{~km}$ at midlatitudes.

The infrared data are used to obtain wind vectors to advect microwave-derived rainfall rates when no microwave data are available at a grid point. The wind vectors are estimated from the spatial correlations of successive geostationary satellite IR fields. For a given precipitating system, its shape and rainfall rate between microwave sweeps over 30-minute intervals are determined by a timeweighted interpolation between the microwave-derived rainfall rates advected from the previous one. It is possible to obtain precipitation estimates any time daily. Specific algorithms and scripts are used to convert datasets into ASCII files.

The CMORPH was successfully used to study the diurnal cycle of convection in La Plata Basin [36] and Amazon Basin [37] and applications for water management of large watersheds [20]. The CMORPH dataset is useful for a broad spectrum of studies between $60^{\circ} \mathrm{S}$ and $60^{\circ} \mathrm{N}$. The results of several authors on inherent errors of this rainfall estimate are satisfactory and allow a more detailed analysis of tropical dynamics, especially where surface observations are scarce. The CMORPH technique uses different sensors and satellites to yield the best rainfall estimation possible, as described in the following sections. The objective of this study is to integrate $24 \mathrm{hr}$ CMORPH rainfall estimates with respective daily rain gauge measurements over Brazil.

2.3. Rain Gauge Datasets. The spatial distribution of rain gauges in the Brazilian regions (North, Northeast, CentralWest, Southeast, and South) is seen in Figure 1. The lowest rain gauge density is in the North region while the highest is in Southeast, but even within each region, the density varies greatly with the highest density in São Paulo State and the lowest in Acre State. The record length of each rain gauge station is also variable. All rain gauge measurements are limited by spatial representativeness and exposure [38]. Daily precipitation accumulations were used in this research to minimize these two sources of error.

This research used all datasets available between 2000 and 2015 that met minimum quality standards. Some rain gauges present more than 100 years of daily measurements. Table 1 presents a synthesis concerning the area of each state, the total number of rain gauges in record, the ones used in this work after basal data quality control, the resulting average distance between rain gauges, and the percentage of the total number of rain gauges left after removing those with missing records and poor quality measurements. Although Brazil has a total of 11,427 rain gauges, less than $65 \%$ of them were used.

The average distance between rain gauges is about $50 \mathrm{~km}$. For daily accumulation analysis, it would be fairly good if the density would not vary so greatly in the country. These high state and regional discrepancies are related to the demographic density (highest in Southeast and lowest in North) and water resources usage for agriculture, hydroelectric power generation, and consumption, among others, 
but also due to a lack of federal public policy for meteorology and hydrology in the country.

For instance, there are six federal institutions dealing with meteorology and hydrology issues, several state and municipal agencies, and other private companies that keep surface measurements of weather and hydrology variables without a common policy on network design, systems specification, and data transmission, storage, and formatting and quality assurance, as well as calibration laboratories and data review and documentation. These limiting factors just on the rain gauge network configuration result in an increased measurement error and lack of quality control standards for all rain gauge networks in Brazil.

\subsection{Precipitation Analysis}

2.4.1. The Statistical Objective Analysis Scheme (SOAS). The SOAS developed in [24] to integrate weather radar precipitation estimation and rain gauge measurements is used in this research work to integrate CMORPH $24 \mathrm{hr}$ precipitation estimation and the Brazilian rain gauge network measurements. Figure 2 shows a schematic on how CMORPH areal precipitation estimates at a given point $P_{\mathrm{a}}$ are integrated with rain gauge point precipitation estimates $P_{\mathrm{o}}$.

The analysis equation is given as follows [24]:

$$
P_{\mathrm{a}}\left(x_{i}, y_{i}\right)=P_{\mathrm{b}}\left(x_{i}, y_{i}\right)+\sum_{k=1}^{K} W_{i k}\left[P_{\mathrm{o}}\left(x_{k}, y_{k}\right)-P_{\mathrm{b}}\left(x_{k}, y_{k}\right)\right] \text {, }
$$

where $P_{\mathrm{a}}\left(x_{i}, y_{i}\right)=$ analyzed precipitation $(\mathrm{mm})$ at grid point $i$; $P_{\mathrm{b}}\left(x_{i}, y_{i}\right)=$ CMORPH precipitation estimation $(\mathrm{mm})$ at grid point $i ; P_{\mathrm{o}}\left(x_{k}, y_{k}\right)=$ rain gauge precipitation measurement $(\mathrm{mm})$ at station point $k ; P_{\mathrm{b}}\left(x_{k}, y_{k}\right)=\mathrm{CMORPH}$ precipitation estimation $(\mathrm{mm})$ at station point $k ; W_{i k}=a$ posteriori weight; $K=$ number of rain gauges; and $\left(x_{i(k)}, y_{i(k)}\right)=$ coordinates $(\mathrm{km})$ for grid point $i(k)$.

A posteriori weights are obtained by assuming that observation and the background errors are uncorrelated and unbiased. Thus, the expected analysis error variance derived from Equation (1) is minimized in relation to a posteriori weights. A full derivation is available in [24]. The normalized expression for a posteriori weights is given as follows:

$$
\sum_{k=1}^{K} W_{k}\left[\rho_{i k}+\varepsilon_{i}^{2}\right]=\rho_{i o}
$$

where $\rho_{i k}=$ background error cross-correlation at stations $i$ and $k ; \rho_{i o}=$ background error cross-correlation at grid points $i$ and $o$; and $\varepsilon_{i}^{2}=$ normalized observation error.

The expected analysis error variance (NEXERVA) is normalized and given by

$$
\varepsilon_{a}^{2}=1-\sum_{k=1}^{K} \rho_{i o} W_{i} .
$$

The normalization is obtained with the background error covariance [24]. The equation above is the normalized

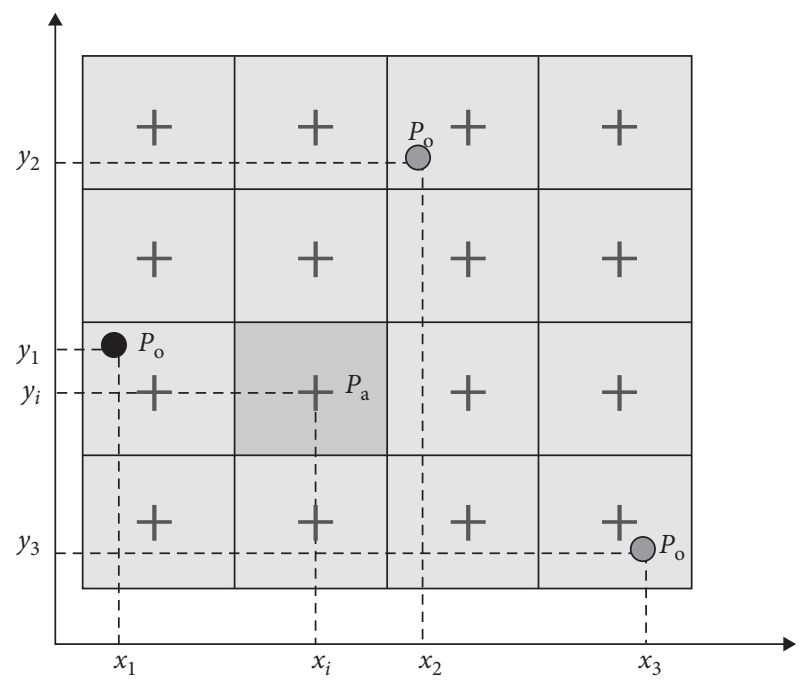

FIGURE 2: Schematic of the geometry of satellite areal rainfall estimates $(4 \times 4$ squares $)$ and three rain gauges $\left(P_{\mathrm{o}}\right)$ around the satellite analysis area centered at point $P_{\mathrm{a}}$ for the SOAS.

expected analysis error variance for each analysis point (pixel). The 2D structure of NEXERVA indicates the spatial error structure. If the first assumption used in deriving $a$ posteriori weights is satisfied, then errors in CMORPH rainfall estimates are independent of the rain gauge errors. If the second assumption is not completely satisfied, then the rain gauges tend to underestimate rainfall at all rainfall rates added the effect of wind and wetting losses [39]. CMORPH errors are not spatially independent, but errors caused by physical characteristics of the precipitation systems $[20,40]$ are an important component of the total error. So, possible biases might be neglected for long time series as the ones used in this work.

\subsubsection{Background Error Correlation. CMORPH $24 \mathrm{hr}$} rainfall accumulation estimates were used to calculate the isotropic background error correlation. The advantage of CMORPH datasets is the higher spatial $(\sim 8 \mathrm{~km})$ and temporal $(30 \mathrm{~min})$ resolutions. There are $133,000 \mathrm{CMORPH}$ pixels over Brazil and about 10,500 rain gauges. The background error correlation between two pixels is given [24] by

$$
\rho\left(d_{k, l}\right)=\frac{\left\langle\left(P_{\mathrm{r}}^{k}-P_{\mathrm{t}}^{k}\right)\left(P_{\mathrm{r}}^{l}-P_{\mathrm{t}}^{l}\right)\right\rangle}{\sqrt{\left\langle\left(P_{\mathrm{r}}^{k}-P_{\mathrm{t}}^{k}\right)^{2}\left(P_{\mathrm{r}}^{l}-P_{\mathrm{t}}^{l}\right)^{2}\right\rangle}},
$$

where $P_{\mathrm{r}}^{k(l)}=\mathrm{CMORPH}$ rainfall accumulation at pixel $k(l)$; $P_{\mathrm{t}}^{k(l)}=$ long-term CMORPH rainfall accumulation mean at pixel $k(l)$; and $d_{k, l}=$ distance between CMORPH pixels $k$ and $l$.

The total number of points used to determine sample correlations is a function of the number of pairs for which there is at least one with measurable precipitation. The correlation curve as a function of distance for different time intervals of precipitation accumulation is constructed by averaging all the correlation estimates for a given distance to 


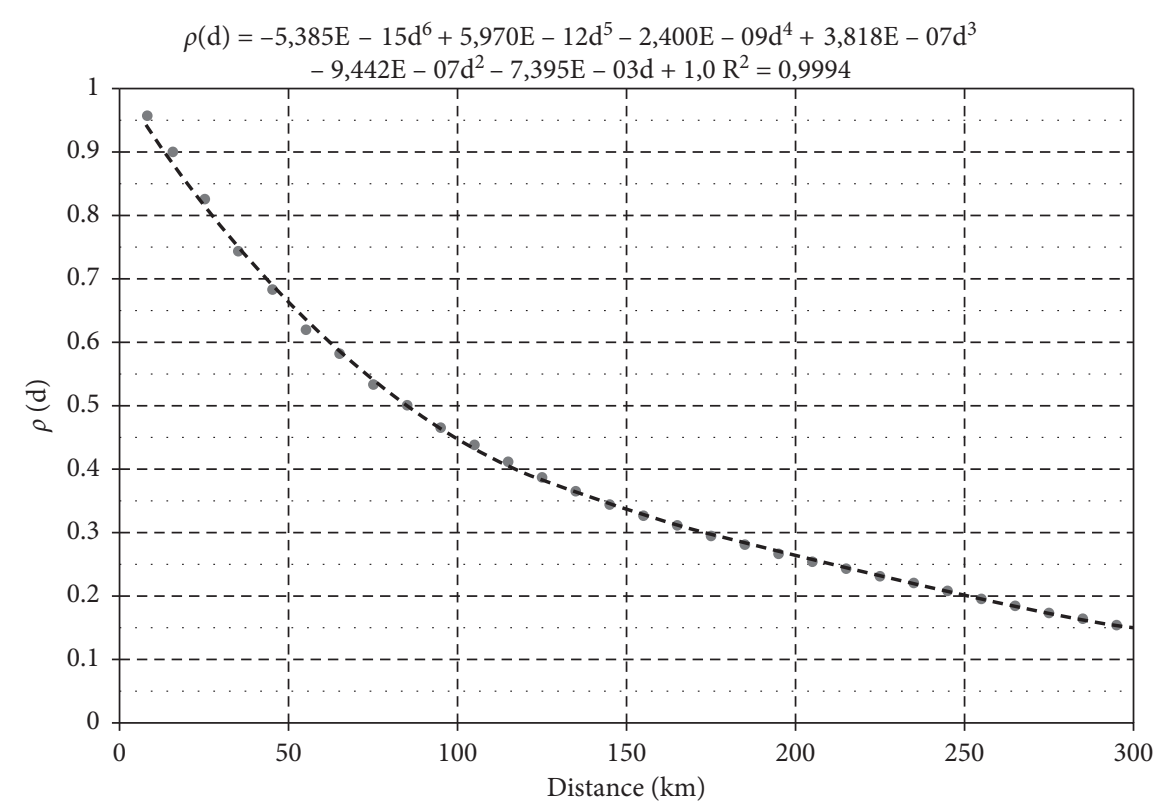

FIGURE 3: Adjusted correlation function between two pixels of CMORPH 24 hr precipitation time series between 2000 and 2015 over Brazil. The sixth-order polynomial coefficients and the variance coefficient adjusted by the minimal square fit are indicated.

obtain the isotropic component of the spatial correlation. A six-order polynomial function was fitted to the distanceaveraged correlations [24]:

$$
\rho(d)=a_{0}+a_{1} d+a_{2} d^{2}+a_{3} d^{3}+a_{4} d^{4}+a_{5} d^{5}+a_{6} d^{6} .
$$

The best fit satisfies the positive-defined curve necessary for matrix inversions in the SOAS [24]. Figure 3 shows the adjusted $6^{\text {th }}$ order polynomial curve in the range of $0 \mathrm{~km}$ to $300 \mathrm{~km}$. The variance explained by the polynomial fit is 99.94\%.

Only rain gauges with complete precipitation records between 2000 and 2015 were used in this work. Additionally, rain gauge precipitation time series with low correlation $(\rho<$ 0.1 ) with nearest ones were not used in the objective analysis. Table 1 shows the total number of rain gauges for each of the five regions in Brazil. A total of 7,759 out of 11,427 rain gauges (Figure 1) time series were used in this study or $64.7 \%$ of all rain gauges.

The spatial distribution of NEXERVA can be estimated from Equation (3) with the correlation function. Figure 4 shows the spatial distribution of NEXERVA for analysis of three rain gauges $(K=3)$ in Equation (3). NEXERVA is lower for high rain gauge density states (São Paulo, Paraná, Santa Catarina, and Ceará) and higher elsewhere, especially in North Brazil. One rain gauge analysis yield (not shown) has lower overall NEXERVA than three-rain gauge analysis (Figure 4), given the higher interdependency of the three-rain gauge analysis. The density of rain gauges for $24 \mathrm{hr}$ precipitation accumulation is such that just one gauge is enough to reduce errors in general, particularly in states with denser rain gauge networks. The three-rain gauge analysis not only tends to improve the analysis but also reduces the radius of influence of each gauge, since the gauges tend to be less independent of each other.
The regional NEXERVA discrepancies are overwhelmingly large. They could be reduced with the reallocation of rain gauges for a more uniform spatial distribution. This can be accomplished with a suitable public policy for meteorology, through the reorganization of the many independent hydrology and meteorology services into a single hydrometeorological service system (HSS), which would then be maintained and operated by a federal agency of the executive branch.

Such an HSS is urgently needed, since the economy of Brazil is based on water resources for agriculture and hydroelectric power generation. Both of these activities require large volumes of water from midsized watersheds in South and Southeast to large-sized watersheds in North Brazil (Figure 5). In this latter case, several hydroelectric power plants are being constructed to supply energy to the region.

2.4.3. SOAS Verification with MERGE. The precipitation analysis produced with SOAS was verified against the MERGE method [41] that has been used in South America. It combines TRMM 3B42RT precipitation estimates and rain gauge precipitation measurements at $24 \mathrm{hr}$ time resolution and $25 \mathrm{~km}$ spatial resolution through a simple distanceweighted method [41]. The verification was carried out at the watershed scale with daily precipitation averages between January 2000 and December 2015. The number of rain gauges used by MERGE is less than the one used for the present study since the whole rain gauge database is used excluding those with missing data.

\section{Results}

Rain gauge daily rainfall accumulation from 1000 UTC of the previous day to 1000 UTC of the day was integrated with 


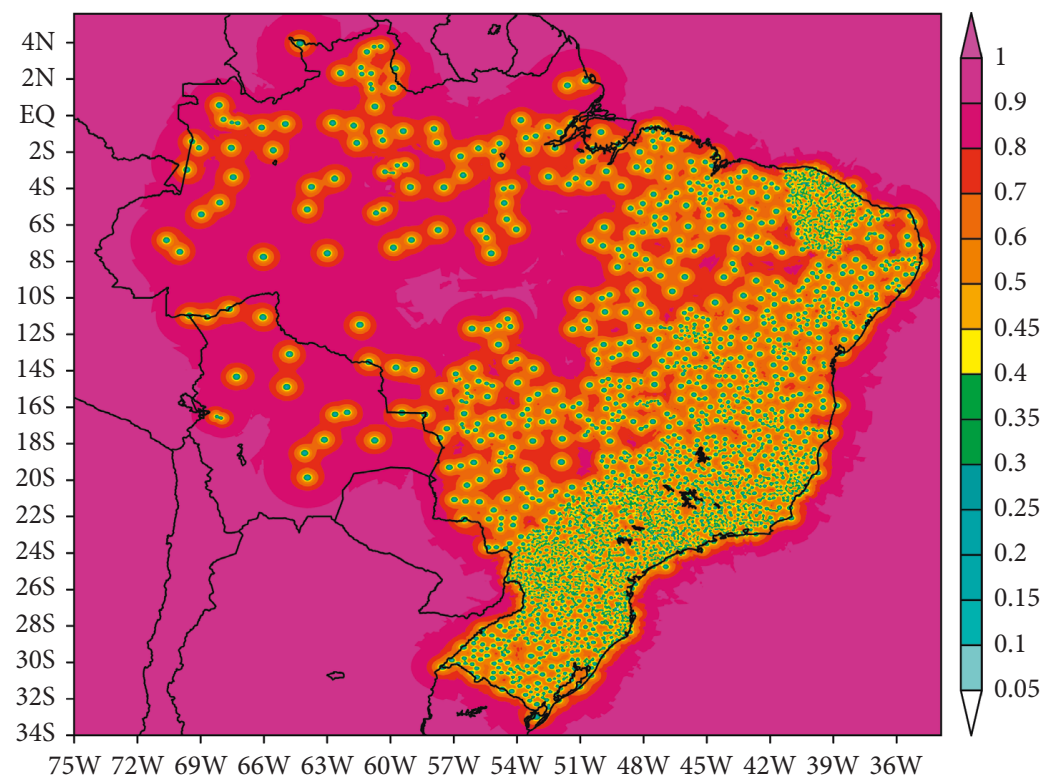

FIGURE 4: Spatial distribution of the normalized error variance (NEXERVA) for daily precipitation accumulation in September 2010 for three-rain gauge analysis with 7,759 rain gauges (Table 1). Country boundaries, latitudes, and longitudes are indicated. Color scale is the NEXERVA.

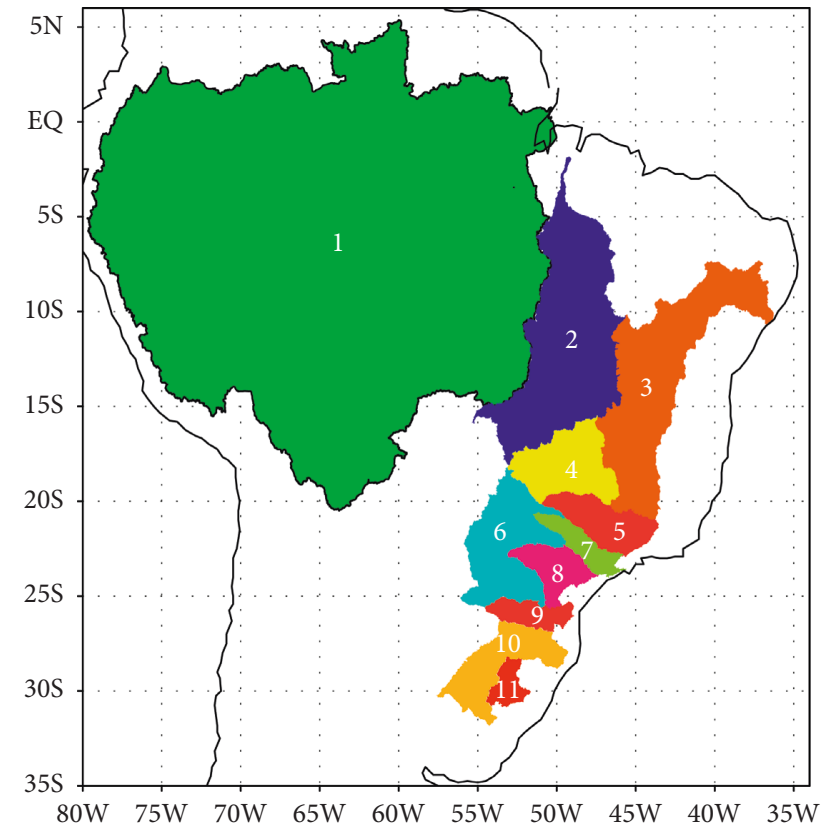

Figure 5: Brazilian watersheds: (1) Amazonas; (2) Tocantins; (3) São Francisco; (4) Paranaíba; (5) Grande; (6) Paraná; (7) Tietê; (8) Paranapanema; (9) Iguaçu; (10) Uruguay; (11) Jacuí. Latitudes, longitudes, and geographic and watershed contours are indicated.

CMORPH daily rainfall accumulation estimation at the same time interval with the SOAS from January 2000 to December 2015. Gridded daily precipitation estimates of CMORPH, SOAS, difference of SOAS minus CMORPH, and NEXERVA fields were integrated with monthly and yearly totals for an overall performance analysis and long-term tendencies. Monthly averages and standard deviation were obtained for each state in Brazil and for eleven Brazilian watersheds.
3.1. Monthly Long-Term Mean Rainfall. Figure 6 shows monthly mean rainfall accumulation for CMORPH original estimates and the difference of SOAS minus CMORPH averaged between 2000 and 2015. The seasonal cycle is apparent in the sequence of monthly precipitation averages, which are driven by major circulation systems such as the intertropical convergence zone (ITCZ) in North Brazil. It is most active at the north most portion in September and at south in April (not shown), with precipitation in excess of $400 \mathrm{~mm}$ along the shores of Pará State. The South Atlantic convergence zone (SACZ) precipitation footprint is apparent between November and March and most active over the Southeast region in January, with a maximum greater than $250 \mathrm{~mm}$. Indeed, SACZ is the most important circulation system for the replenishment of the water supply for the Southeast region, where $40 \%$ of the population and $53 \%$ of the Brazilian GDP are concentrated. Similarly, the mesoscale convective systems (MCSs) are the most important weather feature for South Brazil [42]. They supply precipitation for the watersheds (Figure 5) that feed into the Itaipú hydroelectric power plant, which is responsible for about $25 \%$ of the Brazilian electrical energy supply. Its signature is more evident in April, May, September, and October, when precipitation can be greater than $400 \mathrm{~mm}$.

The south Atlantic high pressure system (SAHPS) over Northeast Brazil inhibits precipitation inland throughout the year. A narrow strip of precipitation occurs along the coast in the region where direct thermal circulations associated with sea and land breezes increase precipitation between April and August. The SAHPS is the main water vapor transport supply system in South America [43], especially for the Amazon watershed. About $60 \%$ of the precipitation is recycled by evapotranspiration and partially transported to the SACZ and MCS regions by low-level jets. Other transient features, such as the diurnal cycle of convection in the 

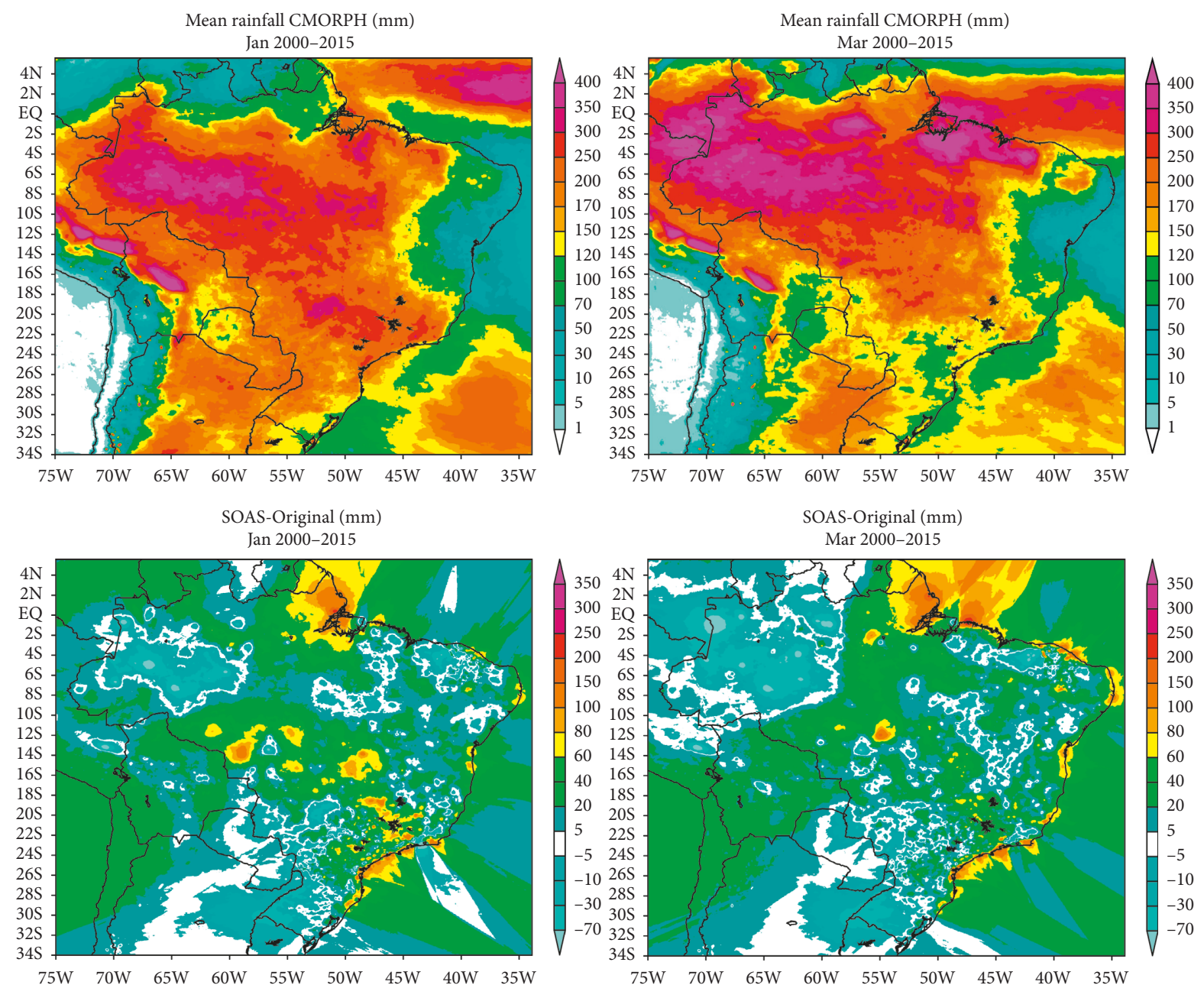

Mean rainfall CMORPH $(\mathrm{mm})$

May 2000-2015
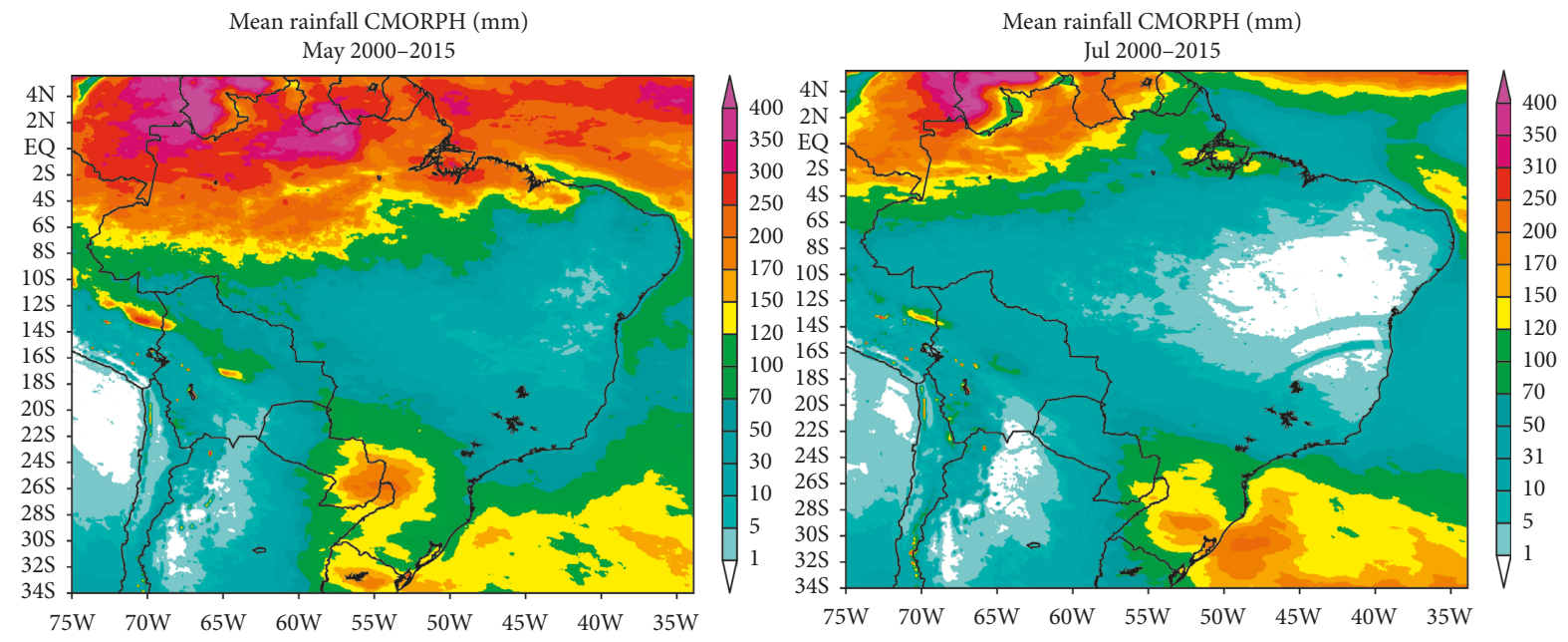

FIgURE 6: Continued. 

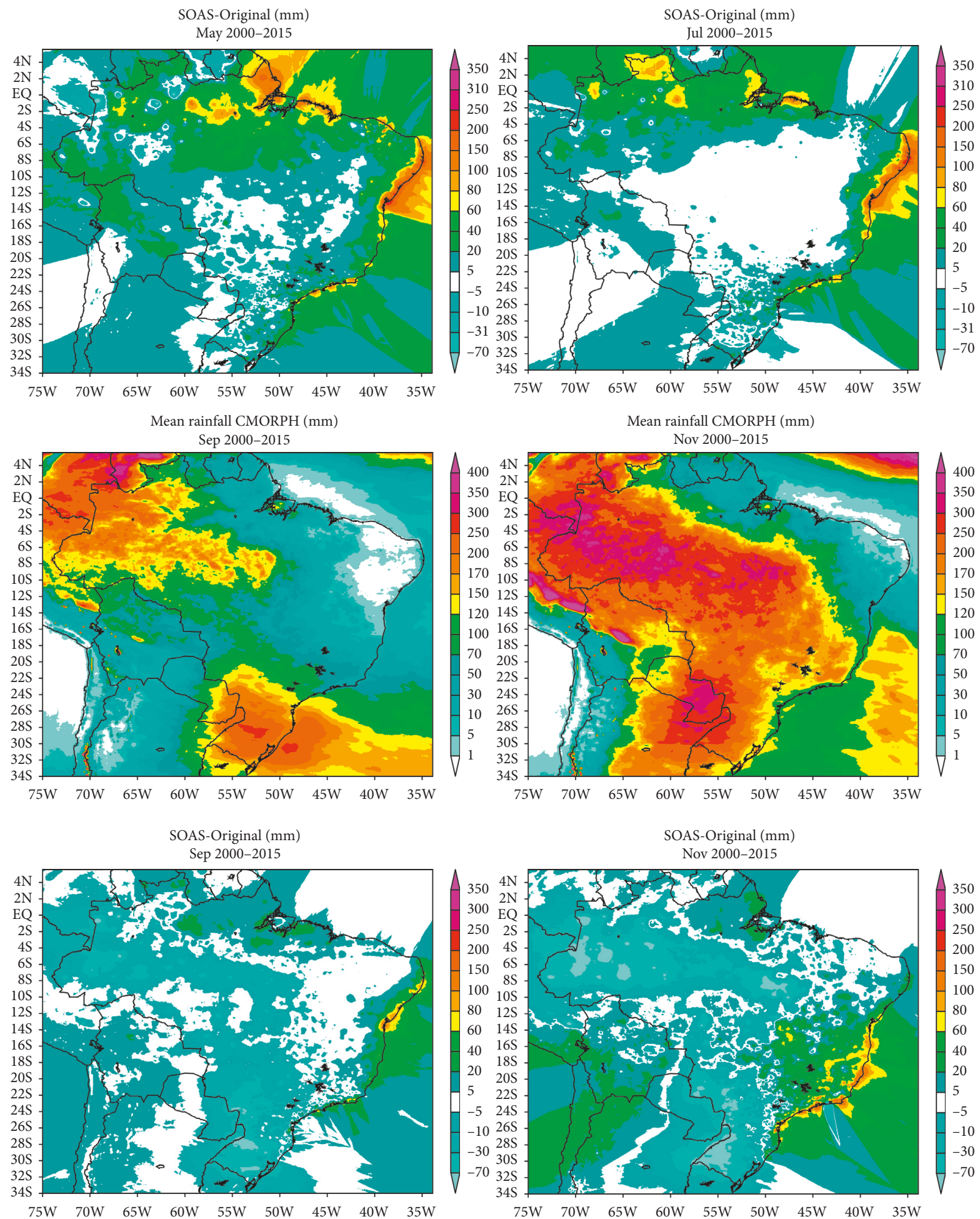

Figure 6: Monthly precipitation accumulation average between 2000 and 2015 for CMORPH (1st, 3rd and 5th rows) and difference field between SOS analysis and CMORPH (2nd, 4th and 6th rows). Months, latitudes, longitudes, and geographic contours are indicated. Color scale indicates precipitation $(\mathrm{mm})$.

Amazon, cold fronts, upper-level lows, easterly waves, and jets, are embedded in the monthly precipitation averages. Since CMORPH datasets have an $8 \mathrm{~km}$ and $30 \mathrm{~min}$ spatiotemporal resolution, these transient weather footprints can be analyzed with the precipitation field [37].
The monthly average precipitation difference field SOAS minus CMORPH is also shown in Figure 6. The amplitude of the differences tends to be higher during spring and summer and lower in fall and winter or proportional to the rainfall accumulation and its 
associated weather systems ranging from isolated deep convection to widespread stratiform rainfall associated with cold fronts and convergence zones. The difference fields for January, March, April, and December are in general positive, with the highest differences over the Central-West and Southeast regions. The largest differences are obtained for the coast of the Northeast region, from April to August, during the so-called rainy season, and for the State of Amapa, from January to May.

In general, the differences are negative in the South in April and August to November. This region is influenced by MCSs, very deep convection that lasts for more than a day and propagates eastward steered by upper-level jets, with water vapor transport associated with southward low-level jets [37]. The difference fields are also negative in Amazonia in February and September to December. Differences tend to be zero in Central Brazil between June and August, during the dry season in winter. Indeed, there is greater coherence between rain gauge measurements and satellite rainfall estimates for no precipitation. CMORPH tends to be positively (negatively) biased in summer (spring) except February (December) with amplitudes greater than the negative ones. The results shown here for coastal areas and high lands in Central Brazil are similar to those found by Rasmussen et al. [42], who compared several satellite precipitation estimates over mountains in Central China and concluded CMORPH had the highest negative biases.

Remarkably, CMORPH is negatively biased along the entire Brazilian coast, especially in Northeast during the rainy season. It is one major deficiency in satellite techniques where warm and shallow precipitating clouds are a dominated feature and yet yield low rainfall rates for many hours. The Brazilian coast is scarped from Rio Grande do Sul to Bahia, where most of the landslides occur during the rainy season. Thus, the integration of CMORPH or any other satellite technique with surface measurements is essential for public safety in the risky sloped terrain of the Serra do Mar mountain ridge.

The interannual variability of yearly precipitation in South America is presented in Figure 7. The precipitation fields were obtained from daily rain gauge measurements and CMORPH estimates integrated by SOAS (Equations (1) and (2)) The SOAS yields better results for contiguous Brazil given its rain gauge network. Other areas are not much influenced by the rain gauge network used in the present study.

Yearly precipitation spatial patterns indicate higher accumulation $(4,500 \mathrm{~mm})$ in northwest Amazonia, downwind from Andes Cordillera (four local maxima), north coast of Amazonia, southern Colombia, and Venezuela. Some precipitation maxima transient features are over Equatorial North Atlantic and Southern Brazil $(3,000 \mathrm{~mm})$. The easterlies transport large volumes of water vapor from Tropical Atlantic Ocean to Amazonia on a daily basis.

Northeast Brazil is the region with the lowest precipitation accumulation given the SAHPS. There is a high precipitation gradient westward between Northeast and North Brazil that marks the transition between semiarid and Amazon rainforest. The driest year was $2015(<600 \mathrm{~mm})$ and the wettest was $2004(>900 \mathrm{~mm})$. The Southeast region is under the influence of SACZ with a more homogeneous precipitation distribution $(1,500 \mathrm{~mm})$, although in 2014 the region was under SAHPS effects and, consequently, experienced one of the worst droughts in recent years. This drought heavily affected the local water supply, sanitation, navigation, and agriculture. Record precipitation occurred in Southern Brazil in 2015 under El Niño, with maximum precipitation in excess of $3,300 \mathrm{~mm}$ in Uruguay.

Noteworthy is the precipitation seesaw between North and South Brazil. When precipitation was maximum in South, in 2002 and 2015 (not shown), it was minimum in Amazonia. The other way around, when it was maximum in Amazonia, in 2008 and 2012 (not shown), it was minimum in South Brazil. There are relative wet years in both North and South (e.g., 2014) and drier ones (e.g., 2006). Drier years tend to be associated with wet conditions in the Northeast region (e.g., 2010). Both regions are strongly affected by El Niño and Southern Oscillation (ENSO) conditions, while over the Southeast region this effect is diverse.

Reservoir of fresh water in South America between Peru and Bolivia (16S; 70W) receives less than $600 \mathrm{~mm}$ of precipitation. It is mostly recycled from evaporation within its watershed. La Niña episodes tend to yield more significant precipitation accumulation [43].

Although outside the rain gauge network domain in Brazil, the impact of the south Pacific high pressure system (SPHPS) is remarkable in west Bolivia, West Peru, Chile, and Argentina, with very dry conditions being reinforced by the upwelling along the west South America coast. Furthermore, the Andes Cordillera blocks the easterlies and further reduces precipitation.

3.2. Watershed Mean Rainfall Analysis. Figure 5 shows main Brazilian watersheds. The largest one is the Amazon watershed (1), with a drainage area of $750,000 \mathrm{~km}^{2}$, extending through Peru, Colombia, Ecuador, Venezuela, Guiana, Suriname, Bolivia, and Brazil, up to the Atlantic Ocean. It is the largest watershed of the planet. The second largest one is the Tocantins (2) watershed, where a new agriculture frontier has been developed in the past decades.

The São Francisco watershed (3) extends from Southeast to Northeast and is the most important drainage system for this semiarid region, where agriculture and hydroelectric power generation are two important activities that move the economy. It is the second densest populated Brazilian watershed, so water supply and sanitation are very critical.

Very dry conditions prevail since 2012 with severe socioeconomic impacts. The other smaller watersheds are in Southeast and South regions, where most of the Brazilian hydroelectric power is produced, as well as agriculture and manufacturing, among other activities. Together, the Southeast and South watersheds correspond to more than $75 \%$ of the Brazilian GDP. These watersheds are part of the La Plata Basin, the second largest watershed system in South America.

Figure 8 shows the daily time evolution of the normalized error variance (NEXERVA) for a three-nearest rain gauge SOAS average over the eleven watersheds considered. 

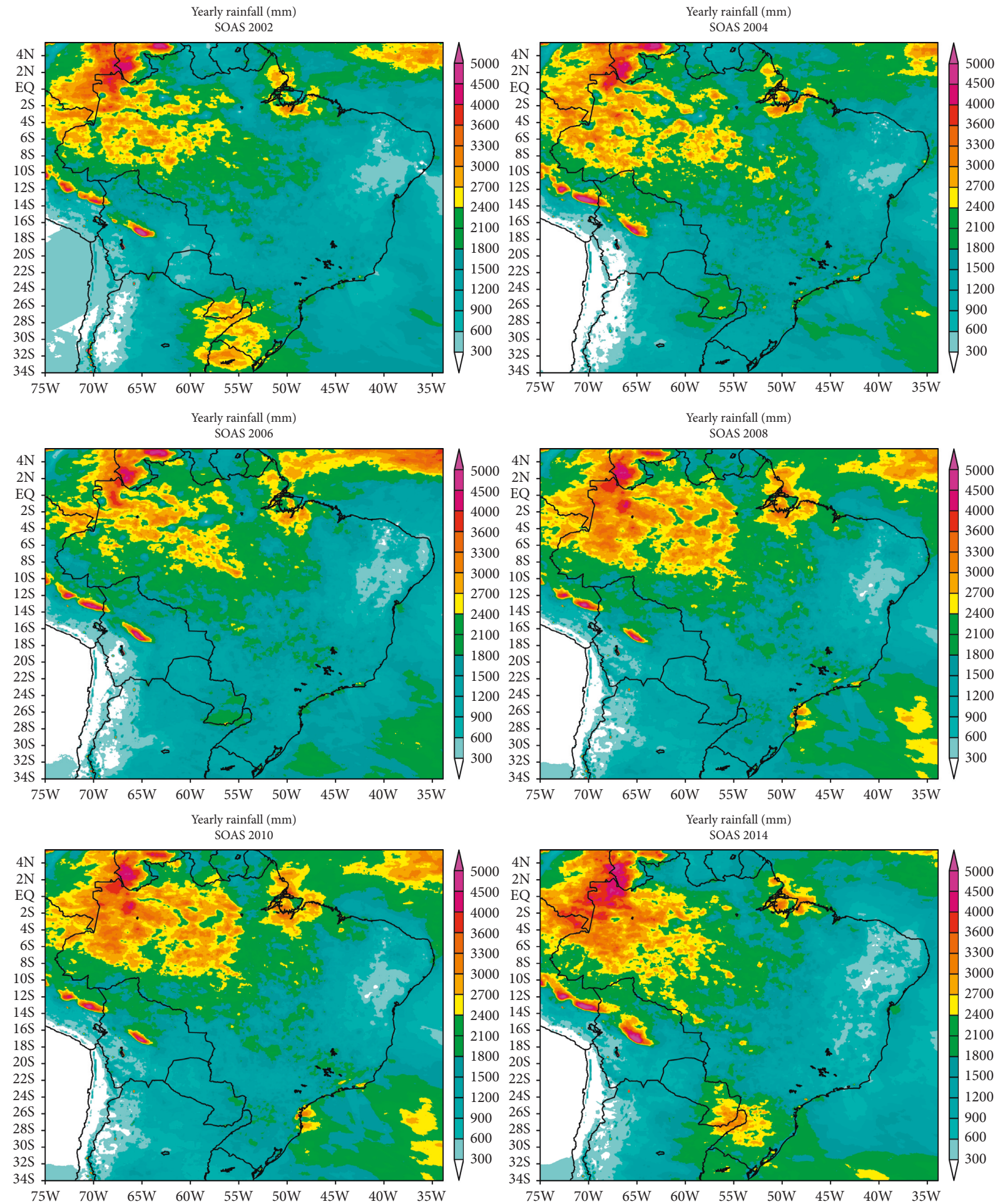

FIGURE 7: Yearly precipitation accumulation obtained with daily SOAS for specific years between 2002 and 2015. Years, latitudes, longitudes, and geographic contours are indicated. Color scale indicates precipitation $(\mathrm{mm})$.

The Amazon watershed has the largest NEXERVA (0.8), while the Iguaçu watershed is the smallest one (0.4).

NEXERVA oscillates from month to month given the variation of the total number of rain gauge data used in SOAS. Rain gauges with one or more missing data in a given month were not used in the analysis for that entire month.
The Amazon watershed has the largest NEXERVA variation, between 0.7 (early 2012) and 0.9 (late 2015). NEXERVA is more cyclic in the Tocantins watershed and has largely increased in late 2015 (not shown). Conversely, the São Francisco watershed has been presenting reduced NEXERVA since mid-2014. Moreover, of the three largest 


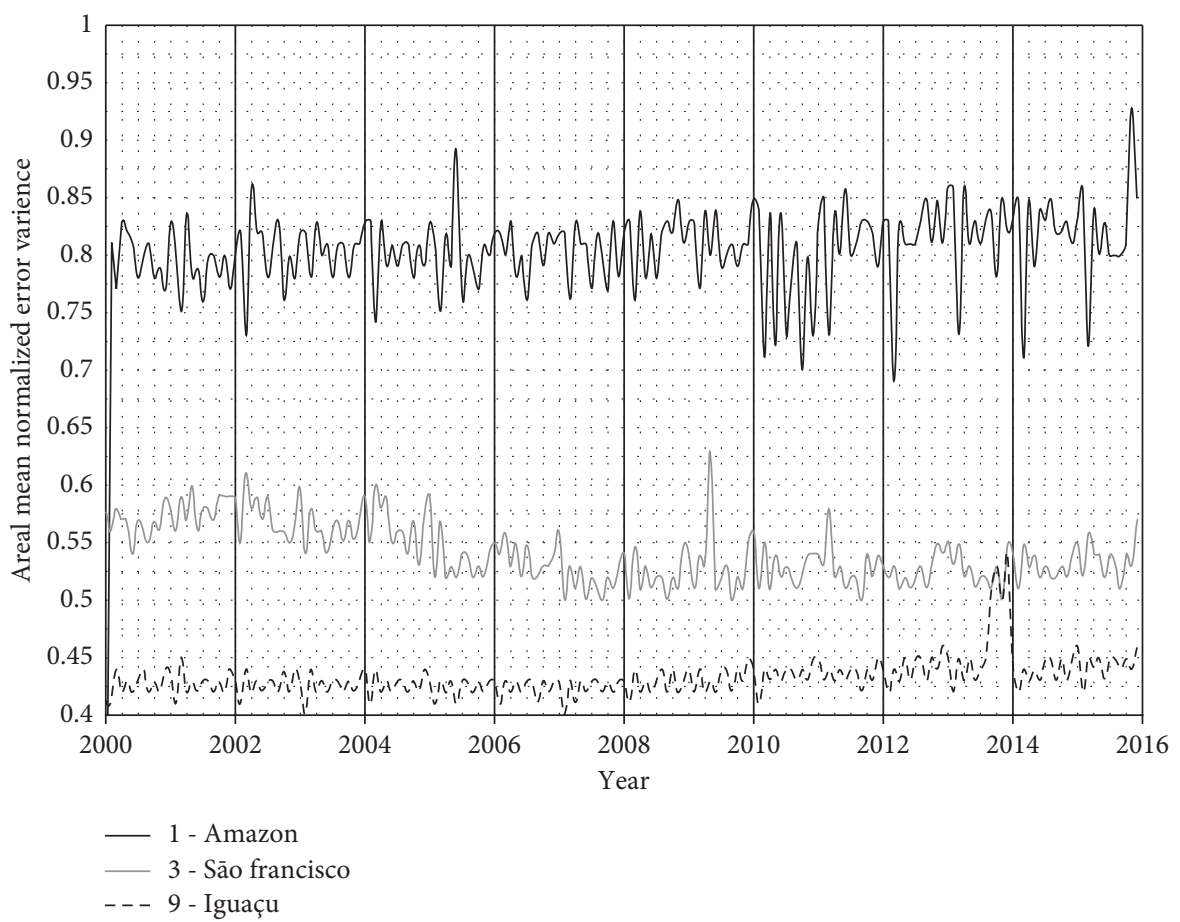

Figure 8: Time evolution of the daily areal mean normalized error variance (NEXERVA) over Amazon, São Francisco, and Iguaçu watersheds (Figure 5) between 2000 and 2015.

Brazilian watersheds, São Francisco is the one that has less month-to-month fluctuations, except in mid-2009 (0.63).

All other eight watersheds have relatively lower NEXERVA, between 0.4 and 0.6 , but with a recent increase due to less rain gauges and missing data. The time evolution of NEXERVA for Paranaiba watershed present peaks almost every year during the mid-way in the rainy season (not shown). The NEXERVA of Grande, Paranaiba, Tietê, and Iguaçu watersheds have a more random fluctuation and smaller amplitudes, but again NEXERVA increases during late 2015 as less rain gauges were available. Indeed, it takes six or more months for some data to be uploaded into the database. Uruguay and Jacuí watershed had an NEXERVA increase in late 2008, late 2010, and 2011 (not shown). Both watersheds have data void areas (Figure 4), which increased during these periods.

The SOAS allows an inference of errors, and the most important ones are in North Brazil, i.e., in Amazonia. A number of studies, including basin wide water budget, tend to be heavily affected by errors, given the very low density network. It is a very difficult task to maintain a denser surface network in the Amazon Forest, given its size and complexity. Furthermore, the region is dominated by diurnal cycle of convection and requires a denser network than the Southern Brazil.

The time evolution of monthly areal mean precipitation and the respective areal standard deviation obtained with the SOAS for eleven watersheds (Figure 5) are shown in Figure 9 . The monthly areal mean precipitation is proportional to the total water volume over each watershed, and the areal standard deviation is related to the drainage spatial variability within the basin. It is an important component of the watershed water budget. The divergence of water vapor in the atmosphere is proportional to the difference between evapotranspiration and precipitation over the watershed. It is negative in the Amazon throughout the year and in all other watersheds during the rainy season, given the large mean zonal advection of moisture from the Atlantic Ocean associated with the SAHPS. During fall and winter, i.e., in the dry season, the divergence is positive.

The daily time evolution of the mean area precipitation for the Amazon watershed (Figure 9(a)) shows two peaks in between two years, as the ITCZ moves across the Equatorial region in spring and fall. The later tend to be higher than the former. During 2005, the spring peak occurrence did not cause a severe drought in Amazonas State [44, 45], while in 2009 [46] and 2012, the Amazon river at the confluence of the Solimões river and the Negro in Manaus, the capital of Amazonas, registered a record stage level greater than $10 \mathrm{~m}$ and a record flow rate greater than $220.000 \mathrm{~m}^{3} \mathrm{~s}^{-1}$ in early May. The total volume of precipitation in 2009 estimated with SOAS was 1820 Gton, while the Amazon river discharge to Atlantic Ocean was estimated to be 1050 Gton [47]. Considering the yearly water budget for the Amazon basin, an increase in groundwater storage occurred, which is consistent with that of [48-50] and based on GRACE (Gravity Recovery and Climate Experiment) measurement analysis.

The daily areal precipitation standard deviation is about $40 \%$ of the area mean $(\sim 200 \mathrm{~mm})$. The long-term tendency of the areal precipitation mean in the Amazon watershed is slightly positive, due to an increase in winter precipitation in recent years. One possible explanation is an increase in the meridional flow of water vapor from North Atlantic Ocean 


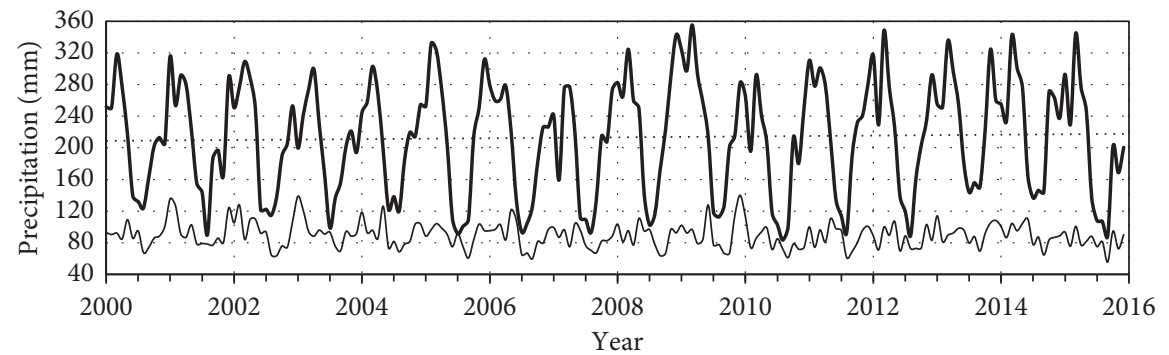

(a)

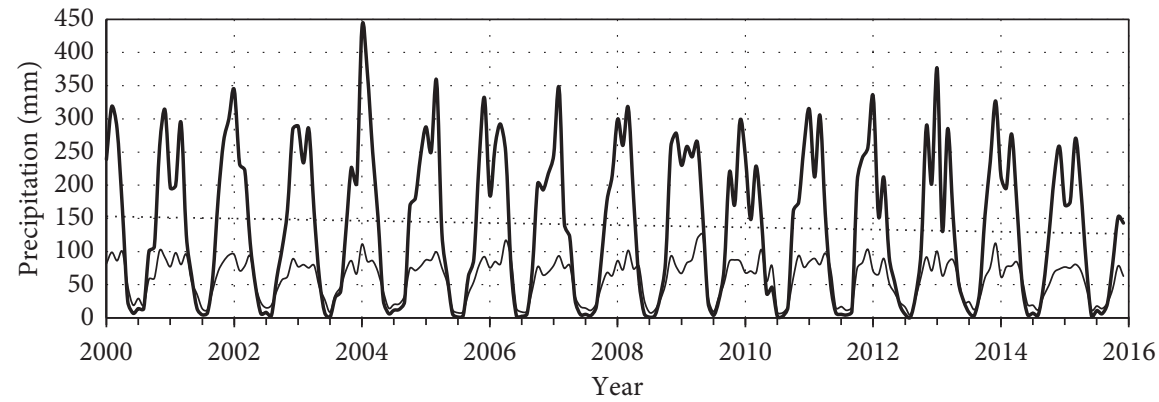

(b)

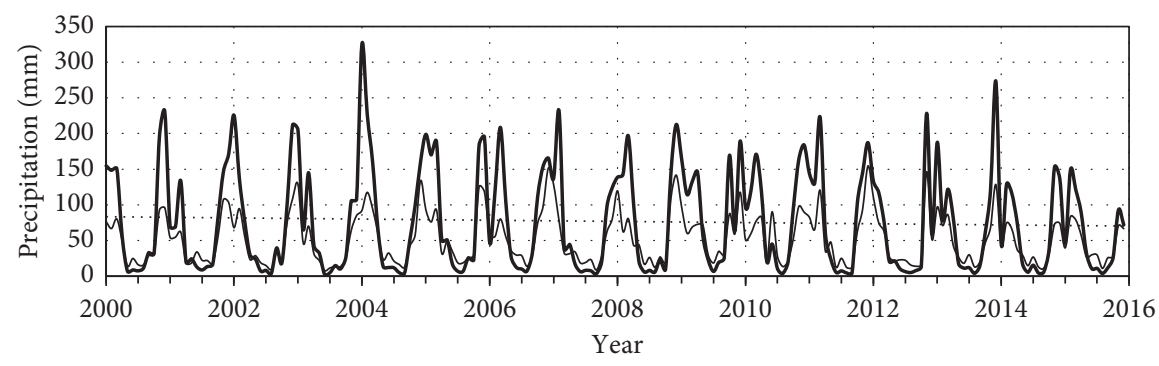

(c)

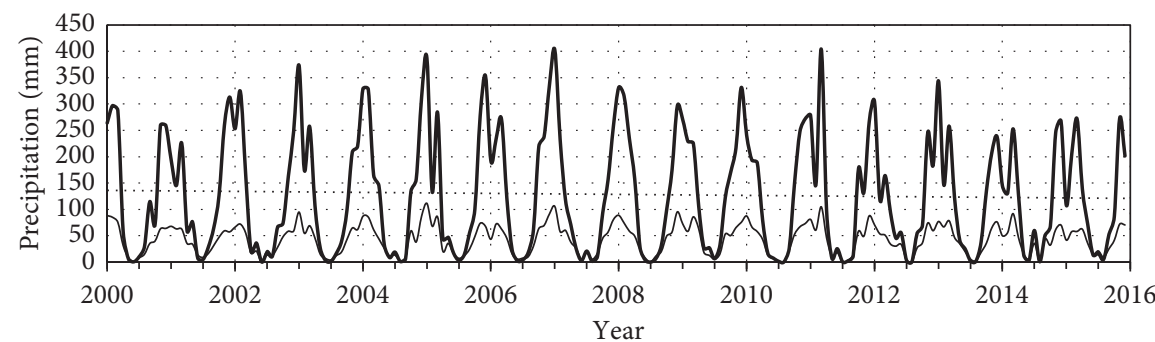

(d)

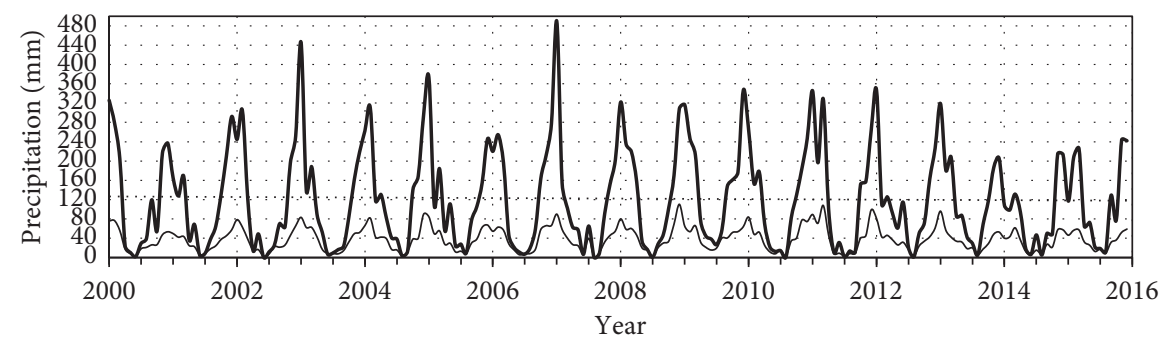

(e)

Figure 9: Continued. 


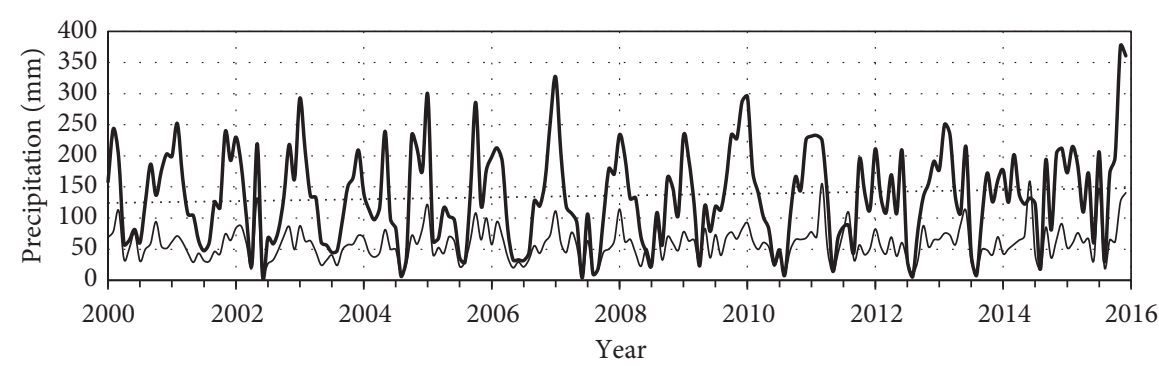

(f)

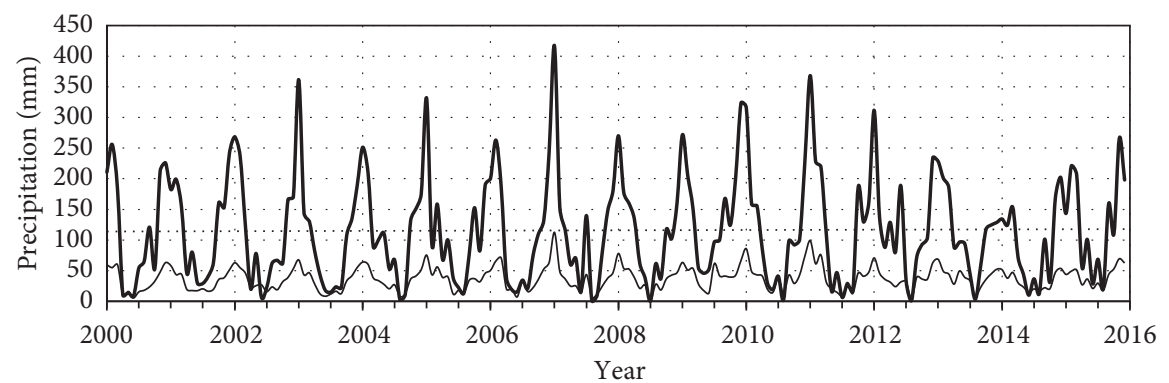

(g)

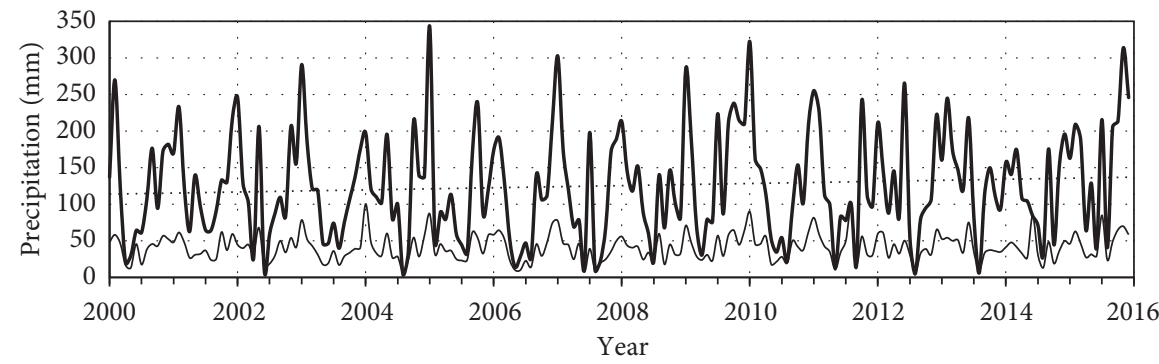

(h)

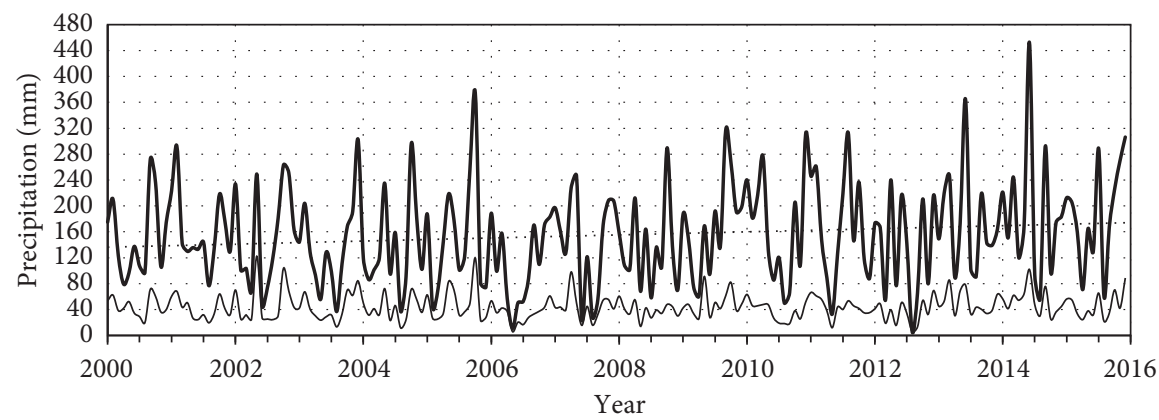

(i)

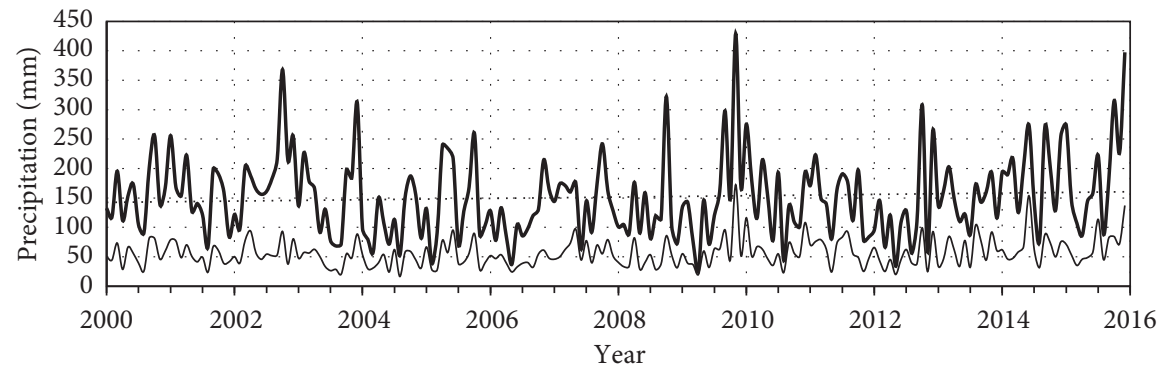

(j)

Figure 9: Continued. 


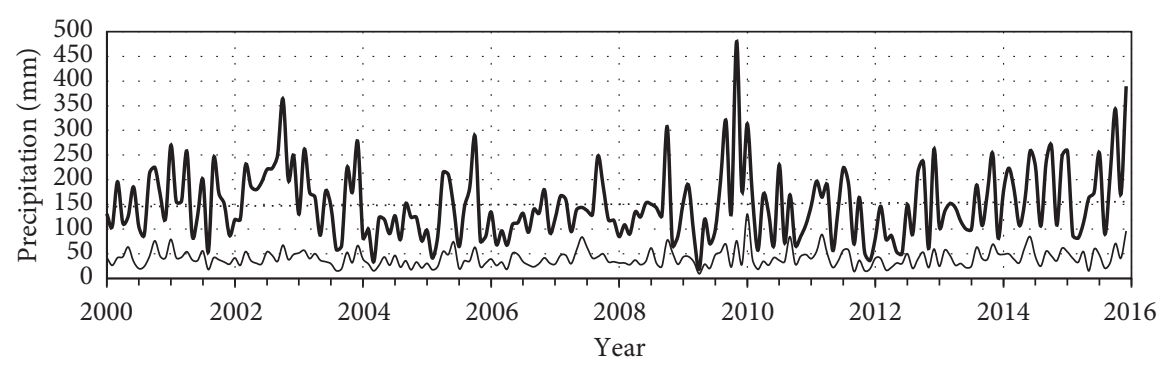

(k)

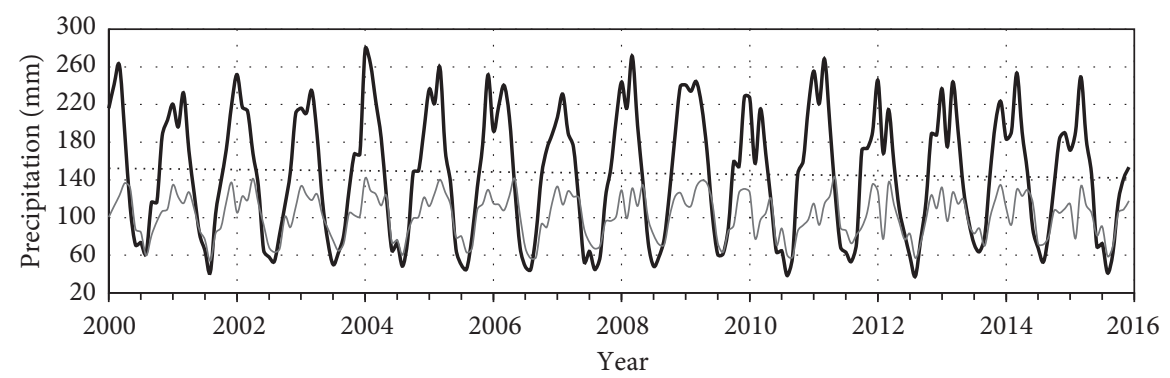

(1)

Figure 9: Time evolution of daily areal mean precipitation (thick line) and the respective standard deviation (light line) of Brazilian Watersheds and the whole Brazil between 2000 and 2015. Long-term monthly mean tendencies (dot line) are also indicated. (a) 1Amazonas. (b) 2-Tocatins. (c) 3-São Francisco. (d) 4-Paranaiba. (e) 5-Grande. (f) 6-Paraná. (g) 7-Tietê. (h) 8-Paranapanema. (i) 9-Iguaçu. (j) 10-Uruguai. (k) 11-Jacuí. (l) Brazil.

during the winters of 2013 and 2014. Similarly, the Tocantins watershed (Figure 9(b)) have a regular annual cycle with a well-defined dry season in winter and wet season in summer, varying from $0 \mathrm{~mm}$ to $300 \mathrm{~mm}$, with a negative tendency, in contrast with the Amazon watershed. The daily areal precipitation standard deviation is about $30 \%$ of the area mean $(\sim 150 \mathrm{~mm})$.

The long-term tendency of the areal precipitation mean in the Tocantins watershed is slightly negative particularly in recent years, given the westward expansion of the SAHPS (Figure 7). The tropical South Atlantic SST anomalies were negative, and the mean zonal wind was weaker (not shown). However, precipitation accumulation reached $450 \mathrm{~mm}$ in January, as a result of the retreat (expansion) of the SAHPS (Amazonia daily convection area) eastward.

Further east is the São Francisco watershed (Figure 5), in which the long-term monthly areal mean precipitation (90 $\mathrm{mm}$ ) has a similar negative tendency, though higher than for Tocantins watershed. A more pronounced areal mean precipitation annual cycle is observed for the São Francisco watershed, with a longer dry season in winter and highly variable summer areal mean precipitation (Figure 9(c)). The time evolution of the areal mean precipitation and its respective spatial standard deviation are strongly related. The latter is about $60 \%$ of the former. The São Francisco headwaters are at Southeast Brazil, where the SACZ is the most important weather rainfall producing system, while at the downstream areas the SAHPS effects prevail and reduce the precipitation amounts. So, the spatial precipitation variance within the São Francisco watershed is highest among the considered watersheds.
Paranaiba, Grande, Tietê, Paranapanema, and Iguaçu watersheds are upstream of Paraná watershed (Figure 5). Paranaiba (Figure 9(d)), Grande (Figure 9(e)), and Tietê (Figure $9(\mathrm{~g})$ ) are in the upper Paraná watershed system and have long-term monthly areal precipitation average of 150 $(\mathrm{mm}), 120(\mathrm{~mm})$, and $110(\mathrm{~mm})$, respectively. They have a remarkable high amplitude during middle of the rainy season, with a slight negative tendency in the long-term monthly areal mean precipitation between 2000 and 2015 in the Paranaiba and almost no tendency for Grande and Tietê.

These watersheds are under the SACZ precipitation regime (e.g., 2006 and 2007), but Paranaiba is influenced by the expansion of the SAHPS (e.g., 2014 and 2015) as shown in Figure 7. The time evolution of monthly areal precipitation means and respective standard deviations vary proportionally more so for the Paranaiba and Grande watersheds. The upper Tietê watershed is also under the sea breeze circulation near the coast of São Paulo State. This direct thermal circulation penetrates more than $100 \mathrm{~km}$ in land, yielding additional precipitation during summer months (Figure 6).

Paraná (Figure 9(f)), Paranapanema (Figure 9(h)), and Iguaçu (Figure 9(i)) monthly areal precipitation mean regimes are highly variable throughout the year with maximum precipitation in early summer. Their long-term monthly areal precipitation means are close to $140 \mathrm{~mm}$, with positive tendencies. These watersheds are under SACZ (summer) and MCS (fall and spring) precipitation regimes that yield a highly variable regime. MCSs are supported by two important features, the southward low-level jet (LLJ) and the eastward upper-level jet (ULJ) crossing the Andes 
Cordilleras over the Chaco region [37]. The LLJ advects moisture from the Amazon watershed [51, 52], while the equatorial entrance of the ULJ induces vertical movement and instability for the development of the MCS and propagates long distances.

The Paraná, Paranapanema, and Iguaçu contribution to the yearly precipitation was highest in 2015 (Figure 7) during the intense 2014/2015 El Niño episode. So, while the Amazon watershed had significant reduction in precipitation (Figure 9(a)) late in 2015, these three watersheds had a concomitant increase in precipitation a seesaw behavior. For instance, during the intense La Niña 2008/2009 [53], higher (lower) areal precipitation mean was over Amazon (Paraná) watershed [54]. Nevertheless, the time evolution of the monthly areal precipitation means for both Amazon and Paraná watersheds has a long-term positive tendency. Results in [55] for the Paraná basin between 1986 and 2011 indicate similar positive tendencies.

Similarly, Uruguay (Figure 9(j)) and Jacuí (Figure 9(k)) are under the same precipitation regime of the Paraná, Paranapanema, and Iguaçu watersheds, though with very small long-term monthly areal precipitation mean positive tendency. The precipitation extremes of 2004 (low) and 2009 (high) across the La Plata Basin are consistent with GRACE [56]. The long-term monthly mean for Uruguay and Jacuí is $150 \mathrm{~mm}$. The monthly areal precipitation standard deviation of Paraná and Paraguay watersheds is smaller in amplitude and less correlated to the respective areal precipitation mean, since MCSs are an important contributor to the yearly total precipitation. The daily frequency of precipitation in the southern Brazil is much less than that over northern Brazil [37], but the duration, spatial organization, and span of MCS tend to reduce the precipitation spatial variability.

Finally, the overall long-term monthly areal precipitation for Brazil is $150 \mathrm{~mm}$ with a slight negative tendency between 2000 and 2015. The highest peaks occurred in summer in 2004, 2008, and 2011, while the lowest troughs in winter in 2001,2012, and 2015. Monthly water storage results with GRACE over Brazil for 2003 provided by Tapley et al. [57] are consistent with the SOAS monthly precipitation variation, as well as with [58] for 2003 to 2011. These findings suggest that El Niño episodes tend to decrease the precipitation in winter, while La Niña episodes tend to increase precipitation in summer. Amazon watershed corresponds to $65 \%$ of the Brazil area, and it is heavily affected by ENSO.

The slight negative tendency in the long-term monthly areal precipitation is closely related to drier conditions over Northeast Brazil starting in 2012 (Figure 7), given the impact of the SAHPS. Indeed, it expanded in area in the summer 2014, suppressing the SACZ. The intensity of the SAHPS is related to the overall SST. Negative SST anomalies over the tropical Atlantic Ocean also reduced evaporation and the zonal mean transport of moisture at a minimum during spring and summer 2014 (not shown).

These overall results are consistent with the hydrological cycle over South America and quantify its important component. In this sense, there is moisture convergence $(E-P<0)$ over Brazil in spring and summer, and moisture divergence $(E-P>0)$ in fall and winter, driven by the lower branch of the Hadley circulation that continuously transports moisture from the Atlantic Ocean through the SAHPS to the Amazon watershed and from there to Southern Brazil by LLJs (fall and spring) and to Southeast by SACZs (summer). Finally, and more importantly, the long-term precipitation tendencies shown in Figure 9 qualitatively agree with Figure 1 of [59], which estimated continental scale tendencies of ground water storage between 2002 and 2016 with GRACE.

Figure 10 shows scatter diagrams of monthly areal precipitation mean and the corresponding areal precipitation standard deviation for the eleven watersheds (Figure 5). A power law curve was fitted to the data. The scatter diagrams also show the coefficients of the power law curve and the respective variance coefficients. Overall, higher areal precipitation also means higher areal precipitation standard deviation. The best fits with the highest variance coefficients $\left(\rho^{2}>0.9\right)$ are for Paranaiba, Grande, and Tocantins watersheds. Intermediate ones $\left(0.9<\rho^{2}<0.7\right)$ are for São Francisco, Tietê, Paranapanema, Paraná, and Iguaçu, while the lowest ones $\left(\rho^{2}<0.7\right)$ are for Uruguay, Jacuí, and Amazon watersheds. The scatter diagram for Brazil is also shown in Figure 10. The variance coefficient is $\rho^{2}=0.92$.

So, for Brazil and most of its watersheds, the power law relationship might be a statistical indicator of the areal precipitation variability and of the consistency of the integration analysis. This might be organized in squall lines moving across the watershed in about two and half days and by equatorial waves (e.g., Kelvin and Rossby) lasting several days [37], thus, reducing the spatial variability.

The scattering about the curve might be an indication of errors caused by the rain gauge spatial density (Figure 4 ) and types of precipitating systems, or most probably, both, as suggested by the scatter diagrams of Amazon, Uruguay, and Jacuí watersheds. It is suggested that improving the continuity of measurements, reducing errors caused by exposition of the rain gauges, and increasing the density of the rain gauges might reduce the scattering about the power curve law.

Figure 11 shows the scatter diagram between the average 3 -rain gauge NEXERVA and the respective variance coefficients shown in Figure 10. It indicates that the relationship between the areal precipitation mean and the respective areal precipitation standard deviation increases as the density of the rain gauge network increases, but at higher rain gauge densities, the errors tend to increase, since daily rainfall accumulation measurements are less independent (Figures 3 and 4). Indeed, the best overall results in Figure 11 are for mid-density ran gauge network watersheds.

Figure 12 shows the time evolution of overall monthly difference between SOAS and CMORPH $(\mathrm{mm})$, the respective NEXERVA (\%), and the ratio between the monthly difference and SOAS (\%). NEXERVA fluctuated little about 0.6 between 2000 and mid-2015. Later-2015, it increased to 0.8 , since less datasets were available, given the delay between the measurement and the upload into the database system. The differences vary about zero and tend to be 


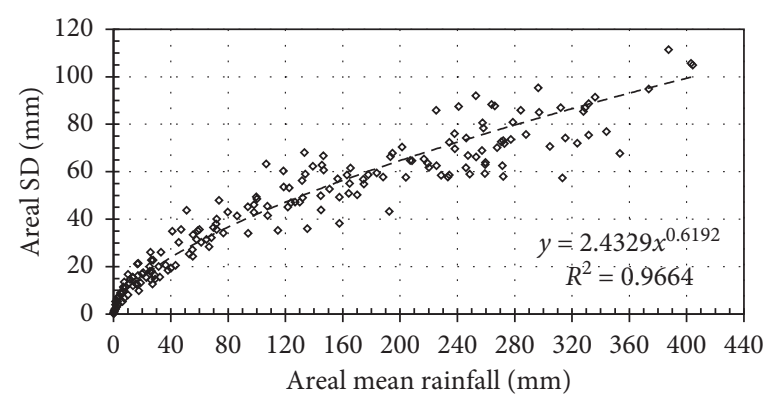

(a)

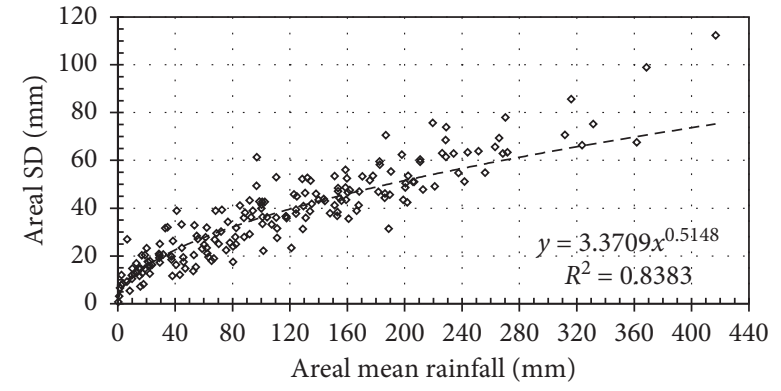

(b)

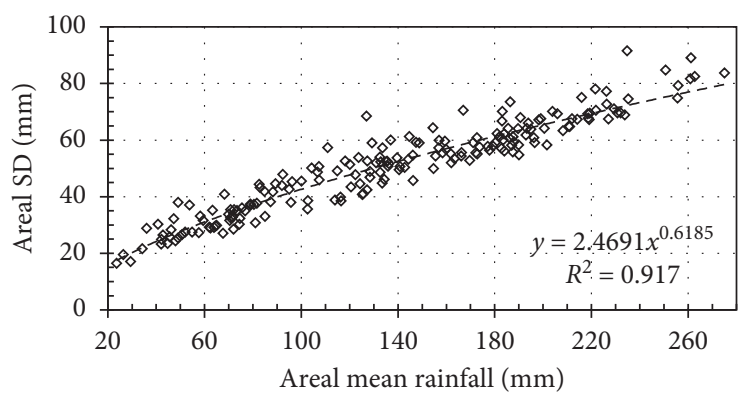

(c)

FIGURE 10: Scatter diagram of SOAS monthly areal mean rainfall against its areal standard deviation (SD) for Paranaiba and Tietê watersheds (Figure 8) and Brazil territory between 2000 and 2015. (a) 4-Paranaíba. (b) 7-Tietê. (c) Brazil.

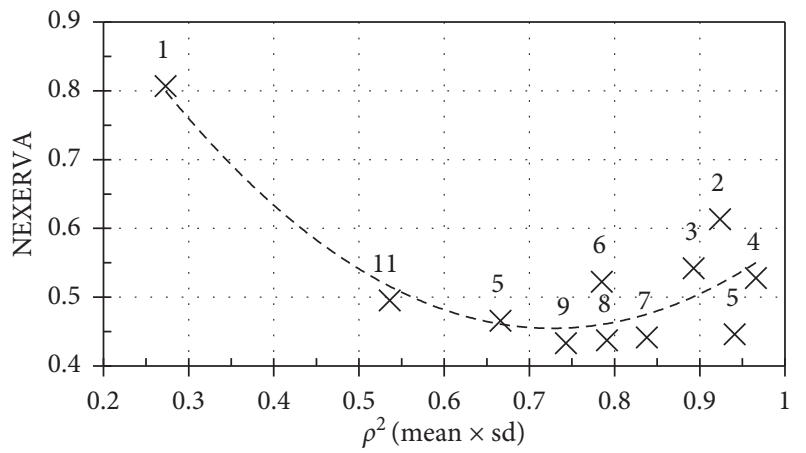

FIGURE 11: Scatter diagram of NEXERVA against the variance coefficient for the eleven watersheds. The number is the watershed specified in Figure 5. The best fit curve is indicated.

positive during the rainy season and negative in the dry season, but it has increasingly become positive with time as a result of CMORPH underestimation previously indicated.

The percentage in difference is about $10 \%$ but can be as high as $50 \%$. In general, it is higher in fall and winter and lower in spring and summer. Thus, CMORPH tends to underestimate daily precipitation in the spring and summer and overestimate it in fall and winter. Though NEXERVA increased in late 2015 , the differences were only $10 \%$. With fewer rain gauge measurements, the SOAS tends to CMORPH precipitation field estimates.

Long-term monthly areal precipitation means, respective areal precipitation standard deviation, and areal precipitation difference SOAS minus CMORPH were also analyzed for Northern, Northeastern, Center-Western, Southeastern, and Southern Brazilian states. Overall, in relation to the SOAS, CMORPH precipitation underestimates over Northeast and Southeast, and overestimates in North, Center-West, and South in spring and in Amazonia in summer.

The statistics indicate the different precipitation regimes are dominated by the annual cycle of convection. For instance, Amazonia has two maxima in March $(301.5 \mathrm{~mm})$ and November $(277.8 \mathrm{~mm})$ and a minimum in August $(92.7 \mathrm{~mm})$, influenced by the North-South movement of the ITCZ. The wet and dry seasons in Northeast Brazil are between April and August and between September and December, respectively. The Center-West states have welldefined annual cycle of precipitation with a rainy season between October and March (spring and summer), and very dry season between June and August (winter), similar to the Southeast. The south states have the smallest annual convection with abundant rain even in winter as a result of the MCS.

3.3. SOAS $\times$ MERGE Applications. Figure 13 shows scatter plots of watershed daily average precipitation ( $\mathrm{mm}$ ) for SOAS and MERGE between January 2000 and December 2015 for Amazonas, São Francisco, Grande, Tietê, and Iguaçu watersheds. MERGE precipitation analysis is lower than SOAS except for Amazonas watershed where the scattering about the linear MSQ fit is also large. The longterm SOAS (MERGE) watershed daily precipitation average for Amazonas, São Francisco, Grande, Tietê, and Iguaçu are $7.0 \mathrm{~mm}(7.3 \mathrm{~mm}), 2.5 \mathrm{~mm}(2.4 \mathrm{~mm}), 4.0 \mathrm{~mm}(3.5 \mathrm{~mm})$, $3.8 \mathrm{~mm}(3.3 \mathrm{~mm})$, and $5.1 \mathrm{~mm}(4.6 \mathrm{~mm})$, respectively. Thus, the long-term average differences vary between $-4 \%$ 


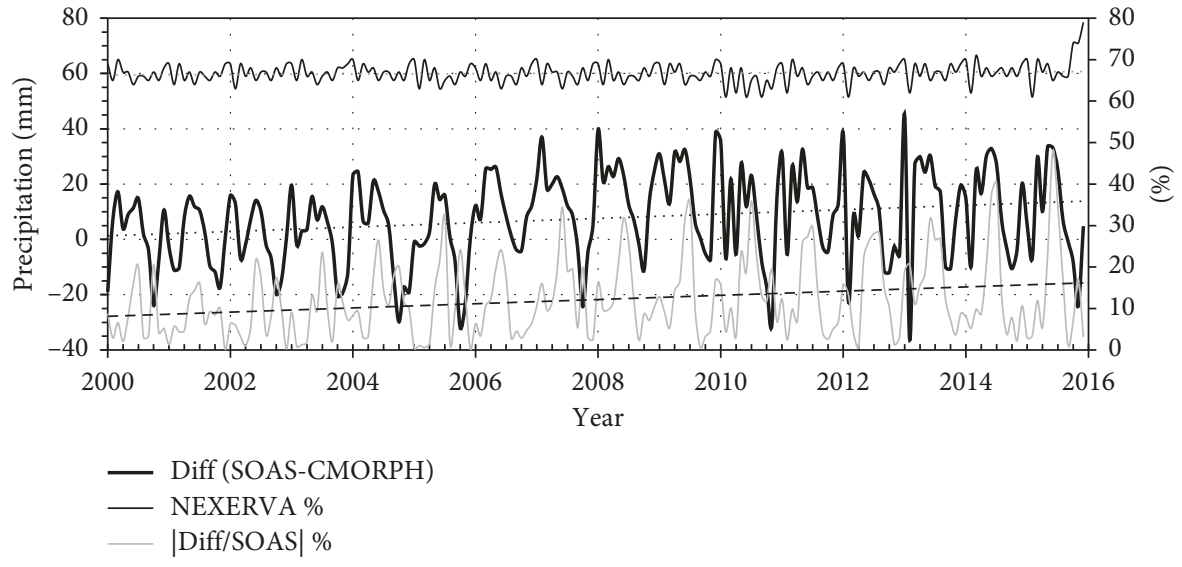

FIGURE 12: Time evolution of daily areal mean precipitation difference SOAS minus CMORPH (left vertical axis) and daily percentage of the difference to SOAS and NEXERVA (right vertical axis) for contiguous Brazil between 2000 and 2015. Linear tendency lines for all variables are indicated.

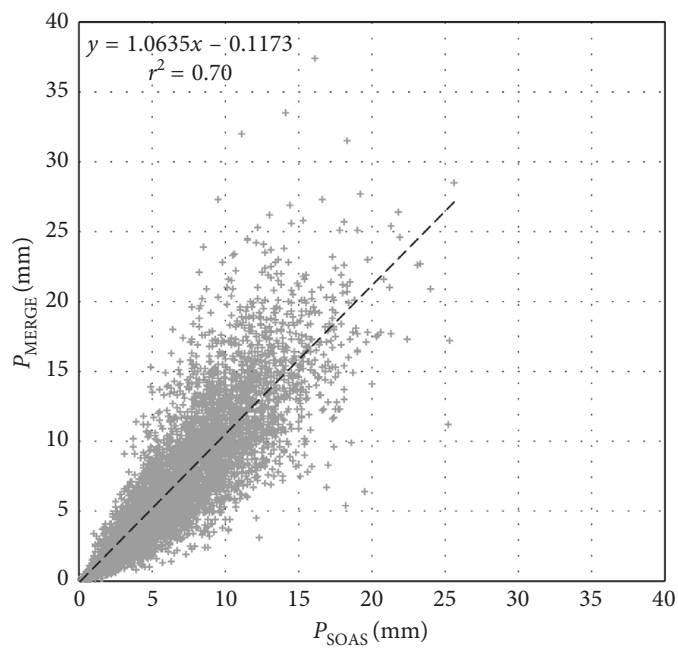

(a)

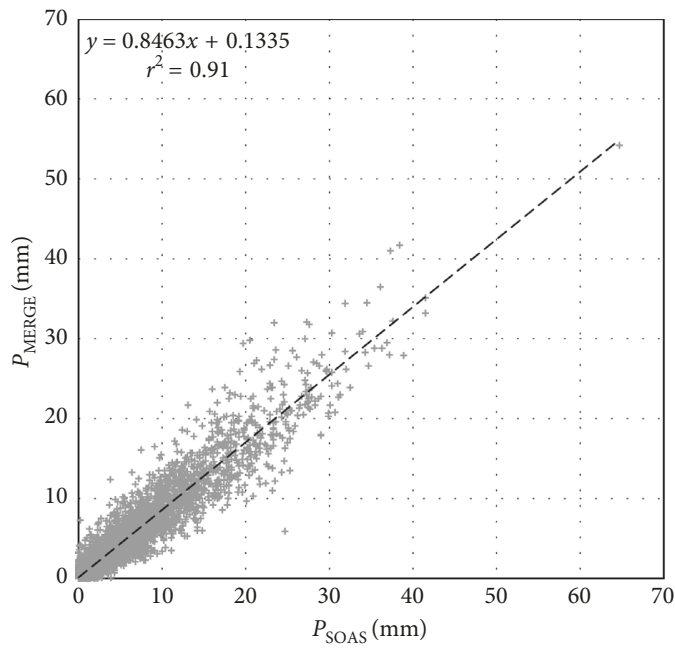

(c)

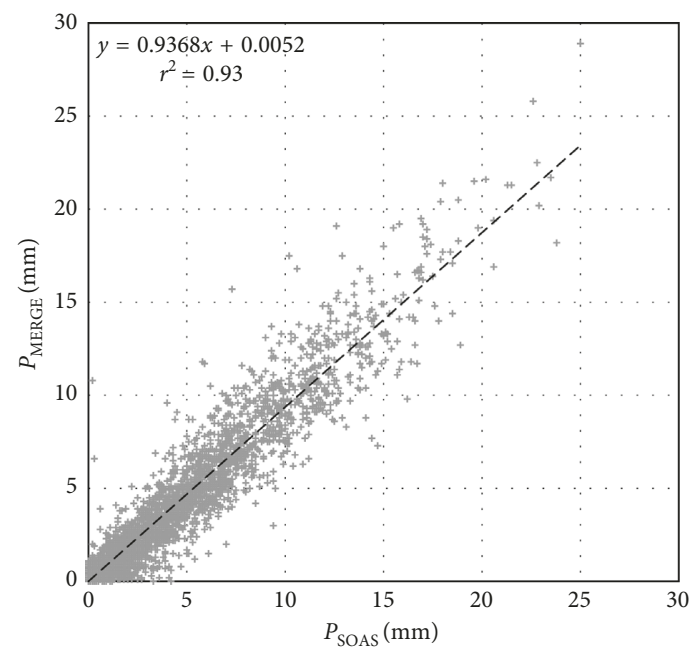

(b)

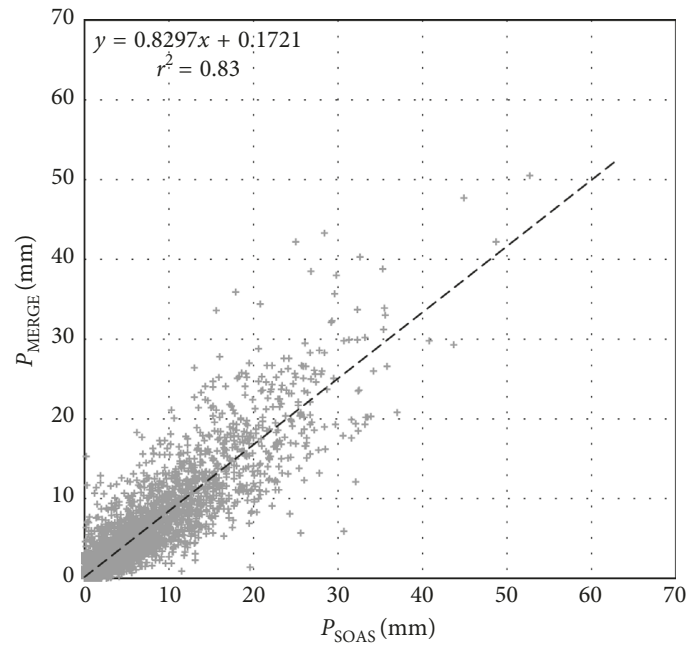

(d)

FIgURe 13: Continued. 


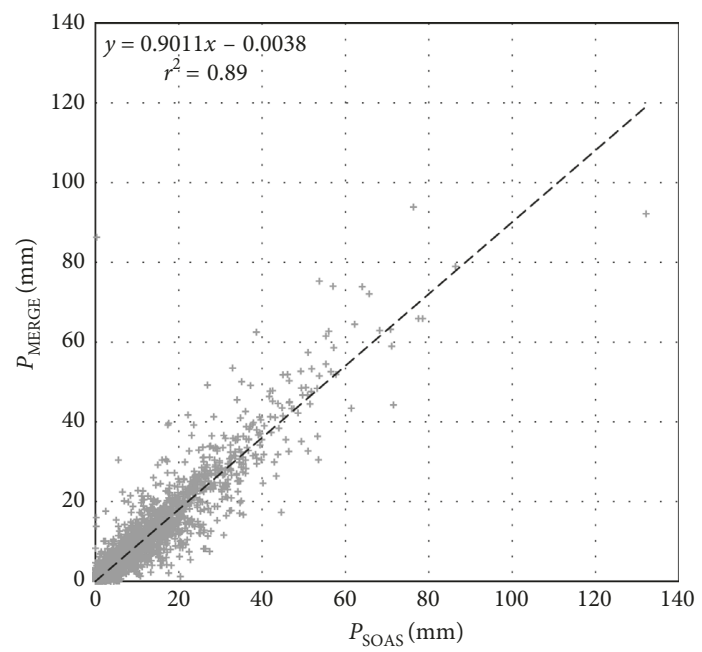

(e)

FIGURE 13: Scatter diagrams of basin average daily precipitation (mm) between SOAS and MERGE from January 2000 to December 2015. It is indicated in the plots the name of the basin (Figure 5), linear MSQ fit, and variation coefficient. (a) Amazonas basin. (b) São Francisco basin. (c) Grande basin. (d) Tietê basin. (e) Iguaçu basin.

(Amazonas basin) and $+15 \%$ (Tietê basin). Since SOAS and MERGE use distinct satellite precipitation estimates at $8 \mathrm{~km}$ and $25 \mathrm{~km}$ spatial resolution, respectively, and are integrated by distinct objective analysis schemes with different rain gauge network densities, the differences are surprisingly small at the watershed level. So, the SOAS has the advantage of having a higher spatial resolution (3 times) and much higher temporal resolution (48 times) that can be used in several applications in hydrologic modeling, mesoscale atmospheric modeling initiation, assimilation, and verification, among other applications such as civil protection shown below.

3.4. SOAS Applications. Figure 14 shows an example of SOAS daily, weekly, monthly, and yearly precipitation accumulation fields for the Paranapanema watershed. It indicates high spatial-temporal precipitation variability at finer spatialtemporal scales compared to other satellite rainfall techniques and single surface rain gauge precipitation analysis. It can be used in hydrologic modeling and verified against independent stage level and streamflow measurements available throughout Brazil. So, the next step forward is testing the SOAS scheme in hydrologic modeling to be published elsewhere.

Finally, monthly and annual frequencies of precipitation episodes with 3-day accumulation greater than $100 \mathrm{~mm}$ were analyzed. It is one of the original goals to study landslides and erosion caused by different types of rainfall episodes of long-lasting stratiform precipitation associated with the first type of soil movement and the second associated but not restricted to intense convective systems [60]. Figure 15 shows the annual spatial distribution of frequencies of precipitation episodes greater than $100 \mathrm{~mm}$ in 3 days (F100D3) between 2000 and 2015.

The risk of landslides [62] is higher in the coastal area [63] of South, Southeast [64-67], and Northeast Brazil and of soil erosion [68] elsewhere in the country. Higher F100D3 (5\%) along the coastal region is located between Paraná and Espírito Santo from November to February, while within Brazil from December to February in North and Southeast Brazil. The fatal landslides mapping shown in Figure 2 of [61] between 2004 and 2013 agrees well with locations of higher F100D3 along the coast of Brazil.

Areas of high frequency of $100 \mathrm{~mm}$ precipitation accumulation in 3 days time interval (F100D3 > 7\%) are located in Pará coast region (February and March), Bolivian and Peruvian Andes Cordillera (October to April), Paraguay and North Argentina (October and November) and South Brazil (September to November). The two major watersheds in South America, the Amazon and La Plata, have the highest frequencies of high accumulation events that have been shaping the landscape through the ages.

The annual distribution of F100D3 in Figure 15 shows higher frequencies along the coast from Espírito Santo to Santa Catarina. The Serra do Mar in Rio de Janeiro had a major landslide in 11 January 2011, where the maximum F100D3 is located. The location of the most frequent landslides in the coast area above is in agreement with F100D3 hotspots of Figure 15.

\section{Discussion}

Since the early satellite rainfall estimates over South America in $[69,70]$, higher spatial-temporal resolutions have become available with CMORPH worldwide [25], among a myriad of techniques [40]. However, CMORPH estimates tend to agree with rain gauge measurements beyond the monthly time scale [20]. Uncertainties in all satellite rainfall estimates [40] as well as in rain gauge measurements $[71,72]$ can be reduced by SOAS first at the daily and second at $30 \mathrm{~min}$ time scales, as suggested by Pereira Fo et al. [24] who originally used SOAS to integrate 


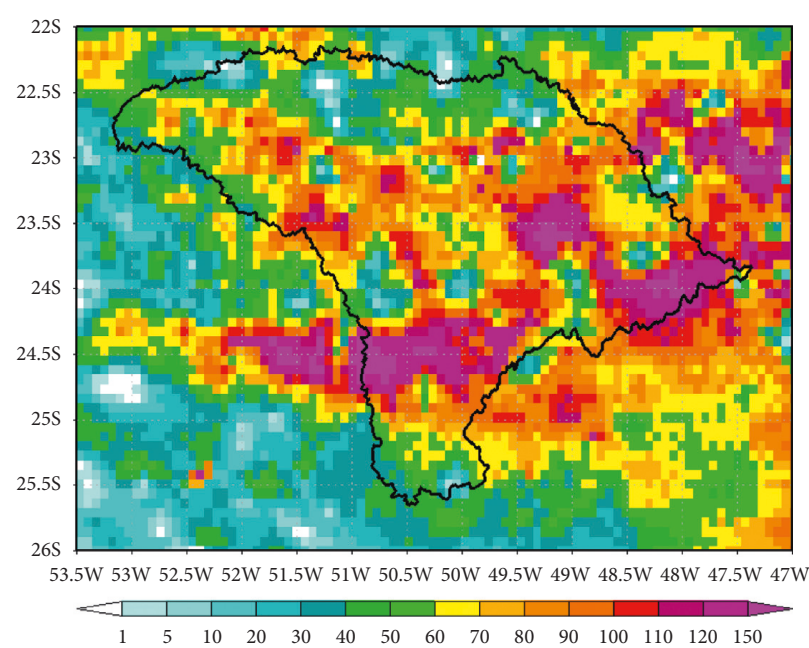

(a)

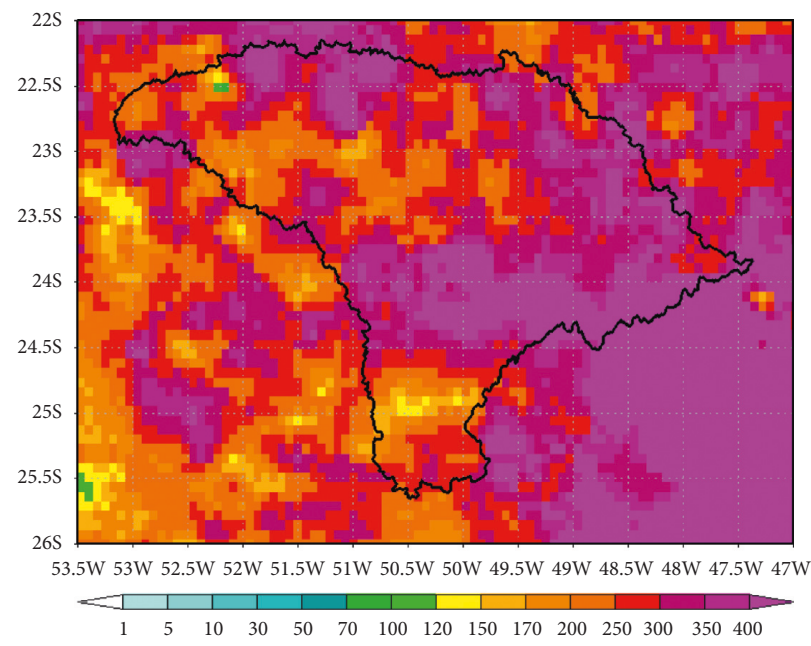

(c)

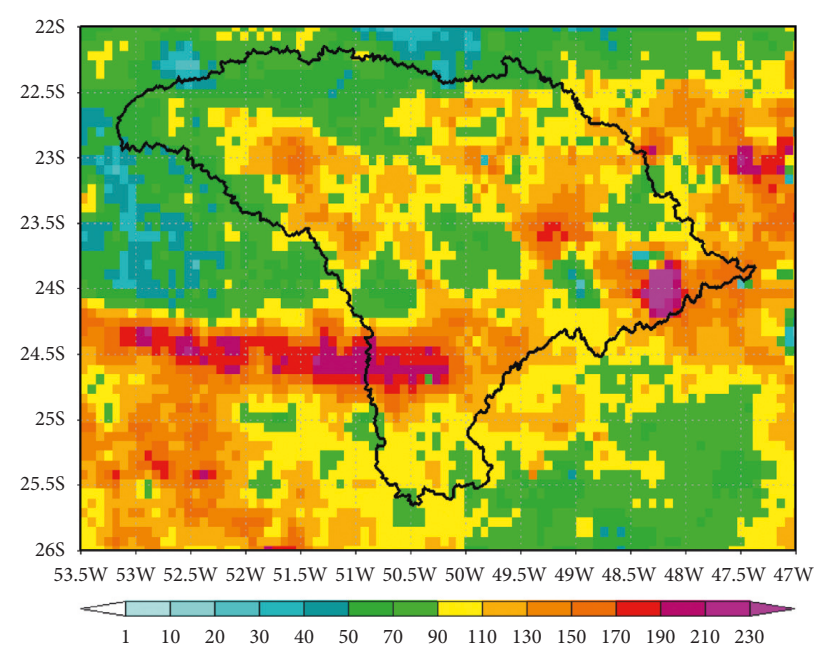

(b)

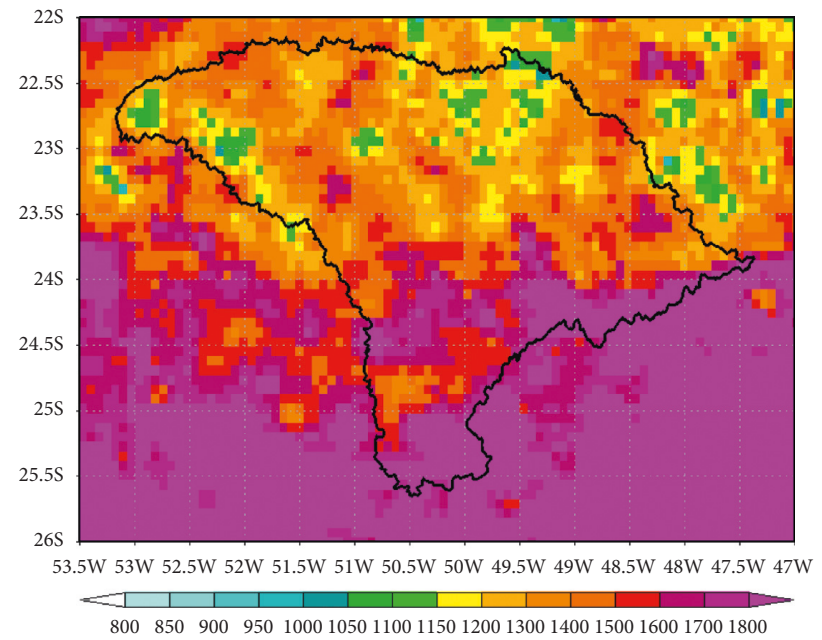

(d)

Figure 14: Precipitation (mm) fields for the Paranapanema Watershed (Figure 5) for daily, weekly, monthly, and yearly accumulation of (a) 25 May 2015, (b) 21 to 27 May 2015, (c) January 2010, and (d) 2010, respectively. Latitudes, longitudes, and watershed contour are indicated. Color scales indicate precipitation accumulation $(\mathrm{mm})$.

weather radar rainfall estimates to rain gauge measurements from $15 \mathrm{~min}$ to $2 \mathrm{hr}$ time scales.

Furthermore, uncertainties in validating instantaneous rainfall estimates with the operational network have been reported in [73] and at relevant scales [74]. The satellite rainfall estimates are being applied to distributed hydrologic modeling in Amazonia [75], and uncertainties tend to propagate to streamflow results. Daily precipitation databases from multisatellite estimates are also applied to climate and hydrologic studies [76].

Our results are consistent with $[40,77-79]$ in other regions and indicate the possibility of integration of CMORPH with other databases. Indeed, other satellite techniques can be merged with SOAS at a common spatialtemporal time scales by a pixel-specific summation of inverse quadratic difference between SOAS and any other precipitation estimation from satellite and weather radar techniques [80].
The integration technique is a step towards integrating multisatellite, weather radar, and surface measurements of precipitation over Brazil and South America, as well as other regions with widely variable spatial-temporal resolution databases. The most important aspect of CMORPH is its spatial-temporal resolution. The SOAS was applied for an $8 \mathrm{~km}$ resolution and 1-day accumulation time scale of rain gauge accumulation time interval. Once the analysis is carried out, a CMORPH pixel-specific weight ratio between the original CMORPH and SOAS estimation can be used to adjust the $30 \mathrm{~min} \mathrm{CMORPH}$ original rainfall rate. It than can be used in many hydrological $[80,81]$ and hydrometeorological applications [82-84] for initialization, assimilation, and verification. Future research can be developed over data sparse areas of the globe such as South America, Africa, and Asia.

The SOAS can also incorporate spatial anisotropies, seasonal and regional characteristics of weather systems and 


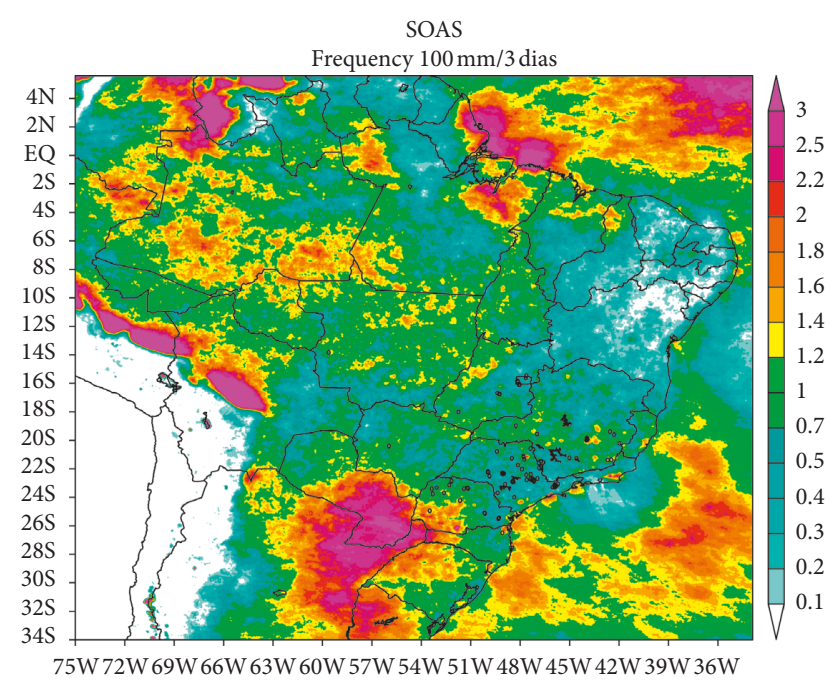

FIGURE 15: Annual spatial frequency distributions of 3-day precipitation episodes greater than $100 \mathrm{~mm}$ between 2000 and 2015 . Latitudes, longitudes, and geographic contours are indicated. Color scale indicates frequencies (\%). Black circles indicate the location of erosion events between 2005 and 2015, and black crosses indicate the location of major landslides between 2004 and 2013 as in [61].

weather types, stratiform and convective systems, and the accumulation time interval for longer periods of time. The method can be used in almost real time with a lower density automatic rain gauge network.

\section{Conclusions}

The SOAS has been used to integrate daily rainfall accumulations measured by the Brazilian rain gauge network and the corresponding CMORPH rainfall estimates between 2000 and 2015. CMORPH tends to be cold in most Brazil, specially at the coastal areas. The integration indicates higher discrepancies where the rain gauge is sparse such as over the Amazon watershed but also over denser areas of Southeast Brazil where NEXERVA tends to increase due to the greater interdependency of the daily rainfall accumulation measurements.

NEXERVA is 0.6 for entire Brazil but varies from 0.45 in Southeast to 0.8 in North Brazil. These regional discrepancies are detrimental specially in Amazonia watershed where the diurnal cycle of convection is a dominant feature year long. A public policy is urgently needed given the socioeconomic aspects of the Amazon watershed, the largest drainage system of the planet Earth. Even watershed wide water balance studies carried out in Amazonia recently should be reviewed in the light of this rainfall analysis. Only $65 \%$ of the datasets available were used given data quality issues.

Monthly areal mean precipitation for eleven watersheds within Brazil indicates a slight positive tendency in North and South Brazil and slight negative in Northeast and Center-West Brazil as a result of the SAHPS and its recent cooling and drying. Furthermore, there is a very slight negative tendency in monthly precipitation in Brazil, which is consistent with the recent high latitude cooling in the Southern Hemisphere.

\section{Data Availability}

CMORPH and rain gauge data used to develop this research are available for download at http://www.cpc.ncep.noaa.gov/ products/janowiak/cmorph_description.html and http:// www.ana.gov.br, respectively. The SOAS dataset is available from the corresponding author upon request.

\section{Conflicts of Interest}

The authors declare that they have no conflicts of interest.

\section{Acknowledgments}

The authors are grateful to several Brazilian agencies for providing rain gauge datasets, namely, Agência Nacional a Águas (ANA), Instituto Nacional de Meteorologia (INMET), and Departamento de Águas e Energia Elétrica de São Paulo (DAEE) as well as to Climate Prediction Center (CPC) of the National Oceanic and Atmospheric Administration (NOAA) for providing CMORPH high-resolution datasets. This research was funded by Petrobras (Grant 2014/ 00438-9). The first author is sponsored by Conselho Nacional de Desenvolvimento Científico e Tecnológico (CNPq) (Grant 302349/2017-6).

\section{References}

[1] S. Durrieu and R. F. Nelson, "Earth observation from space-the issue of environmental sustainability," Space Policy, vol. 29, no. 4, pp. 238-250, 2013.

[2] C. Kidd and V. Levizzani, "Status of satellite precipitation retrievals," Hydrology and Earth System Sciences, vol. 15, no. 4, pp. 1109-1116, 2011.

[3] J. Shanhu, R. Liliang, Y. Bin, H. Yang, Y. Xiaoli, and Y. Fei, "Evaluation of latest TMPA and CMORPH precipitation products with independent rain gauge observation networks over high-latitude and low-latitude basins in China," Chinese Geographical Science, vol. 26, no. 4, pp. 439-455, 2016.

[4] B. Kumar, K. C. Patra, and V. Lakshmi, "Daily rainfall statistics of TRMM and CMORPH: a case for trans-boundary river basin," Journal of Earth System Science, vol. 125, no. 5, pp. 919-934, 2016.

[5] Y. Cai, C. Jin, A. Wang et al., "Comprehensive precipitation evaluation of TRMM 3B42 with dense rain gauge networks in a mid-latitude basin, northeast, China," Theoretical and Applied Climatology, vol. 126, no. 3-4, pp. 659-671, 2016.

[6] G. Skok, N. Zagar, L. Honzak, R. Zabkar, J. Rakovec, and A. Ceglar, "Precipitation intercomparison of a set of satellite and -derives datasets, ERA interim reanalysis, and a single WRF regional climate simulation over Europe and the North Atlantic," Theoretical and Applied Climatology, vol. 123, no. 12, pp. 217-232, 2016.

[7] P. Salio, M. P. Hobouchian, Y. G. Skabar, and D. Vila, "Evaluation of high-resolution satellite precipitation estimates over southern South America using a dense rain gauge network," Atmospheric Research, vol. 163, pp. 146-161, 2015.

[8] Y. Zhang, D.-J. Seo, E. Habib, and J. McCollum, "Differences in scale-dependent, climatological variation of mean areal 
precipitation based on satellite and radar-gauge observations," Journal of Hydrology, vol. 522, pp. 35-48, 2015.

[9] R. Zubieta, A. Getirana, J. C. Espinoza, and W. Lavado, "Impacts of satellite-based precipitation datasets on rainfall-runoff modeling of the western Amazon basin of Peru and Ecuador," Journal of Hydrology, vol. 528, pp. 599-612, 2015.

[10] D. C. Buarque, R. C. D. Paiva, and R. T. Clarke, "A comparison of Amazon rainfall characteristics derived from TRMM, CMORPH and the Brazilian national rain gauge network," Journal of Geophysical Research, vol. 116, no. D19, 2011.

[11] E. Habib, A. T. Haile, Y. Tian, and R. J. Joyce, "Evaluation of the high-resolution CMORPH satellite rainfall product using dense rain gauge observations and radar-based estimates," Journal of Hydrometeorology, vol. 13, no. 6, pp. 1784-1798, 2012.

[12] Y. Luo, W. Qian, R. Zhang, and D.-L. Zhang, "Gridded hourly precipitation analysis from high-density rain gauge network over the Yangtze-Huai rivers basin during the 2007 Mei-yu season and comparison with CMORPH," Journal of Hydrometeorology, vol. 14, no. 4, pp. 1243-1291, 2013.

[13] Y. Shen, P. Zhao, Y. Pan, and J. Yu, "A high spatiotemporal gauge-satellite merged precipitation analysis over China," Journal of Geophysical Research: Atmospheres, vol. 119, no. 6, pp. 3063-3075, 2014.

[14] B. J. Sohn, H.-J. Han, and E.-K. Seo, "Validation of satellitebased high-resolution rainfall products over the Korean Peninsula using data from a dense rain gauge network," Journal of Applied Meteorology and Climatology, vol. 49, pp. 701-714, 2010.

[15] D. Stampoulis and E. N. Anagnoustou, "Evaluation of global satellite rainfall products over continental Europe," Journal of Hydrometeorology, vol. 13, no. 2, pp. 588-603, 2011.

[16] Y. Tian and C. D. Peters-Lidard, "A global map of uncertainties in satellite-based precipitation measurements," Geophysical Research Letters, vol. 37, no. 24, article L24407, 2010.

[17] V. Maggioni, M. P. Sapiano, and R. F. Adler, "Estimating uncertainties in high-resolution satellite precipitation products: systematic or random error?," Journal of Hydrometeorology, vol. 17, no. 4, pp. 1119-1129, 2016.

[18] K. J. Tobin and M. E. Bennett, "Validation of satellite precipitation adjustment methodology from seven basins in the continental United States," JAWRA Journal of the American Water Resources Association, vol. 48, no. 2, pp. 221-234, 2012.

[19] A. Vera and R. Terra, "Combining CMORPH and rain gauges observations over the Rio Negro basin," Journal of Hydrometeorology, vol. 13, no. 6, pp. 1799-1809, 2012.

[20] A. J. P. Filho, R. E. Carbone, J. E. Janowiak et al., "Satellite rainfall estimates over South America-possible applicability to the water management of large watersheds," Journal of the American Water Resources Association (JAWRA), vol. 46, no. 2, pp. 344-360, 2010.

[21] K. O. Winemiller, P. B. McIntyre, L. Castello et al., "Balancing hydropower and biodiversity in the Amazon, Congo, and Mekong basin-scale planning is needed to minimize impacts in mega-diverse rivers," Science, vol. 351, no. 6269, pp. 128-129, 2016.

[22] T. Kelsie and D. Kaplan, "The changing hydrology of a dammed Amazon," Science Advances, vol. 3, no. 11, article e1700611, 2017.

[23] G. J. Huffman, R. F. Adler, D. T. Bolvin et al., "The TRMM multisatellite precipitation analysis (TMPA): quasi-global, multiyear, combined-sensor precipitation estimates at fine scales," Journal of Hydrometeorology, vol. 8, pp. 38-55, 2007.

[24] A. J. Pereira Fo, K. C. Crawford, and C. L. Hartzell, "Improving WSR-88D hourly rainfall estimates," Weather and Forecasting, vol. 13, no. 4, pp. 1016-1028, 1998.

[25] R. J. Joyce and P. Xie, "Kalman filter-based CMORPH," Journal of Hydrometeorol, vol. 12, no. 6, pp. 1547-1562, 2011.

[26] G.-Y. Yang and J. Slingo, "The diurnal cycle in the tropics," Monthly Weather Review, vol. 129, no. 4, pp. 784-781, 2001.

[27] B. R. Scanlon, Z. Zhangb, H. Savec et al., "Global models underestimate large decadal declining and rising water storage trends relative to GRACE satellite data," Proceedings of the National Academy of Sciences, vol. 115, no. 6, pp. E1080E1089, 2018.

[28] G. A. Vicente, R. A. Scofield, and W. P. Menzel, "The operational GOES infrared rainfall estimation technique," Bulletin of the American Meteorological Society, vol. 79, no. 9, pp. 1883-1898, 1998.

[29] S. W. Miller, P. A. Arkin, and R. Joyce, "A combined microwave/infrared rain rate algorithm," International Journal of Remote Sensing, vol. 22, no. 17, pp. 3285-3307, 2001.

[30] F. J. Turk, E. E. Ebert, B.-J. Sohn et al., "Validation of a operational global precipitation analysis at short time scales," in Proceedings of 12th Conference on Satellite Meteorology and Oceanography, Long Beach, CA, USA, February 2003.

[31] G. J. Huffman, R. F. Adler, E. F. Stocker, D. T. Bolvin, and E. J. Nelkin, "Analysis of TRMM 3-hourly multi-satellite precipitation estimates computed in both real and post-real time," in Proceedings of 12th Conference on Satellite Meteorology and Oceanography, Long Beach, CA, USA, February 2003.

[32] R. J. Joyce, J. E. Janowiak, P. A. Arkin, and P. Xie, "CMORPH: a method that produces global precipitation estimates from passive microwave and infrared data at high spatial and temporal resolution," Journal of Hydrometeorology, vol. 5, no. 3, pp. 487-503, 2004.

[33] R. R. Ferraro, "SSM/I derived global rainfall estimates for climatological applications," Journal Geophysics Research, vol. 102, no. D14, pp. 16715-16735, 1997.

[34] R. R. Ferraro, F. Weng, N. C. Grody, and L. Zhao, "Precipitation characteristics over land from the NOAA-15 AMSU sensor," Geophysical Research Letters, vol. 27, no. 17, pp. 2669-2672, 2000.

[35] C. Kummerow, Y. Hong, W. S. Olson et al., "The evolution of the Goddard profiling algorithm (GPROF) for rainfall estimation from passive microwave sensors," Journal of Applied Meteorology, vol. 40, no. 11, pp. 1801-1820, 2001.

[36] A. J. P. Filho, R. E. Carbone, and J. D. Tutle, "Convective rainfall systems in the La Plata basin," Atmospheric and Climate Sciences, vol. 4, no. 4, pp. 757-778, 2014.

[37] A. J. P. Filho, R. E. Carbone, J. D. Tutle, and H. A. Karam, "Convective rainfall in Amazonia and adjacent," Atmospheric and Climate Sciences, vol. 5, no. 2, pp. 137-161, 2015.

[38] F. Brock and S. J. Richardson, Meteorological Measurement Systems, Oxford University Press, Oxford, UK, ISBN: 9780195134513, 2001.

[39] P. Y. Groisman and D. R. Legates, "The accuracy of the United Sates precipitation data," Bulletin of the American Meteorological Society, vol. 75, no. 2, pp. 215-227, 1994.

[40] Q. Sun, C. Miao, Q. Duan, H. Ashouri, S. Sorooshian, and K.-L. Hsu, "A review of global precipitation data sets: data sources, estimation, and intercomparisons," Reviews of Geophysics, vol. 56, no. 1, pp. 79-107, 2018. 
[41] J. R. Rozante, D. S. Moreira, L. G. G. de Gonçalves, and D. A. Vila, "Combining TRMM and surface observations of precipitation: technique and validation over South America," Weather and Forecasting, vol. 25, no. 3, pp. 885-894, 2010.

[42] K. L. Rasmussen, M. M. Chaplin, M. D. Zuluaga, and R. A. Houze Jr., "Contribution of extreme convective storms to rainfall in south America," Journal of Hydrometeorology, vol. 17, no. 1, pp. 353-367, 2016.

[43] W. T. Liu, X. Xie, W. Tang, and V. Zlotnicki, "observations of oceanic influence on the annual variation of South American water balance," Geophysical Research Letters, vol. 33, no. 8, article L08710, 2006.

[44] J. L. Chen, C. R. Wilson, B. D. Tapley, Z. L. Yang, and G. Y. Niu, "2005 drought event in the Amazon river basin as measured by GRACE and estimated by climate models," Journal of Geophysical Research, vol. 114, no. B5, article B05404, 2009.

[45] A. C. Thomas, J. T. Reager, J. S. Famiglietti, and M. Rodell, “A GRACE-based water storage deficit approach for hydrological drought characterization," Geophysical Research Letters, vol. 41, no. 5, pp. 1537-1545, 2014.

[46] J. L. Chen, C. R. Wilson, and B. D. Tapley, "The 2009 exceptional Amazon flood and interannual terrestrial water storage change observed by GRACE," Water Resources Research, vol. 46, no. 12, article W12526, 2010.

[47] J. Eom, K.-W. Seo, and D. Ryu, "Estimation of Amazon river discharge based on EOF analysis of GRACE gravity data," Remote Sensing of Environment, vol. 191, pp. 55-66, 2017.

[48] K. Hu, J. L. Awange, Khandu, E. Forootan, R. M. Goncalves, and K. Fleming, "Hydrogeological characterisation of groundwater over Brazil using remotely sensed and model products," Science of the Total Environment, vol. 599-600, pp. 372-386, 2017.

[49] M. J. Tourian, J. T. Reager, and N. Sneeuw, "The total water storage of the Amazon river basin: a first estimate using GRACE," Water Resources Research, vol. 54, no. 5, pp. 3290-3312, 2018.

[50] L. Xavier, M. Becker, A. Cazenave, L. Longuevergne, W. Llovel, and O. C. R. Filho, "GRACE space gravimetry, in situ river level and precipitation data," Remote Sensing of Environment, vol. 114, no. 8, pp. 1629-1637.

[51] M. G. Nascimento, D. L. Herdies, and D. O. De souza, "The South American water balance: the influence of low-level jets," Journal of Climate, vol. 29, no. 4, pp. 1429-1449, 2016.

[52] D. C. Zemp, C.-F. Schleussner, H. M. J. Barbosa et al., "On the importance of cascading moisture recycling in South America," Atmospheric Chemistry and Physics, vol. 14, no. 23, pp. 13337-13359, 2014.

[53] S. Abelen, S. F. Seitz, R. Abarca-del-Rio, and A. Güntner, "Droughts and floods in the La Plata basin in soil moisture data and GRACE," Remote Sensing, vol. 7, no. 6, pp. 73247349, 2015.

[54] H. O. Panarello and C. Dapeña, "Large scale meteorological phenomena, ENSO and ITCZ, define the Paraná river isotope composition," Journal of Hydrology, vol. 365, no. 1-2, pp. 105-112, 2009.

[55] L. Zandonadi, F. Acquaotta, S. Fratianni, and J. A. Zavattini, "Changes in precipitation extremes in Brazil (Paraná river basin)," Theoretical and Applied Climatology, vol. 123, no. 3-4, pp. 741-756, 2016.

[56] A. Pereira and M. C. Pacino, "Annual and seasonal water storage changes detected from GRACE data in the La Plata basin," Physics of the Earth and Planetary Interiors, vol. 212213, pp. 88-99, 2012.

[57] B. D. Tapley, S. Bettadpur, J. C. Ries, P. F. Thompson, and M. M. Watkins, "GRACE measurements of mass variability in the Earth system,” Science, vol. 305, no. 5683, pp. 503-505, 2004.

[58] F. Frappart, L. Seoane, and G. Ramillien, "Validation of GRACE-derived terrestrial water storage from a regional approach over South America," Remote Sensing of Environment, vol. 137, pp. 69-83, 2013.

[59] M. Rodell, J. S. Famiglietti, D. N. Wiese et al., "Emerging trends in global freshwater availability," Nature, vol. 557, no. 7707, pp. 651-659, 2018.

[60] D. Kirschbaum, R. Adler, D. Adler, C. Peters-lidard, and G. Huffman, "Global distribution of extreme precipitation and high-impact landslides in 2010 relative to previous years," Journal of Hydrometeorology, vol. 13, no. 5, pp. 1536-1551, 2012.

[61] S. A. Sepúlveda and D. N. Petley, "Regional trends and controlling factors of fatal landslides in Latin America and the Caribbean," Natural Hazards and Earth System Sciences, vol. 15, no. 8, pp. 1821-1833, 2015.

[62] O. Hungr, S. Leroueil, and L. Picarelli, "The classification of landslide types, an update," Landslides, vol. 11, no. 2, pp. 167-194, 2014.

[63] M. Francionia, J. Coggan, M. Eyre, and D. Stead, "A combined field/remote sensing approach for characterizing landslide risk in coastal areas," International Journal of Applied Earth Observation and Geoinformation, vol. 67, pp. 79-95, 2018

[64] T. D. Nery and B. C. Vieira, "Susceptibility to shallow landslides in a drainage basin in the Serra do Mar, São Paulo, Brazil, predicted using the SINMAP mathematical model," Bulletin of Engineering Geology and the Environment, vol. 74, no. 2, pp. 369-378, 2015.

[65] R. A. T. Gomes, R. F. Guimarães, O. A. Carvalho Jr., N. F. Fernandes, E. A. Vargas Jr., and E. S. Martins, "Identification of the affected areas by mass movement through a physically based model of landslide hazard combined with an empirical model of debris flow," Natural Hazards, vol. 45, no. 2, pp. 197-209, 2008.

[66] R. F. Guimarães, W. P. Machado, O. A. Carvalho Júnior et al., "Determination of areas susceptible to landsliding using spatial patterns of rainfall from tropical rainfall measuring mission data, Rio de Janeiro, Brazil," ISPRS International Journal of Geo-Information, vol. 6, no. 10, p. 289, 2017.

[67] P. I. M. Camarinha, V. Canavesi, and R. C. S. Alvalá, "Shallow landslide prediction and analysis with risk assessment using a spatial model in a coastal region in the state of São Paulo, Brazil," Natural Hazards and Earth System Sciences, vol. 14, no. 9, pp. 2449-2468, 2014.

[68] M. Dorici, C. W. Costa, M. C. P. de Moraes et al., "Accelerated erosion in a watershed in the southeastern region of Brazil," Environmental Earth Sciences, vol. 75, no. 19, p. 1301, 2016.

[69] R. F. Adler and A. J. Negri, "A satellite infrared technique to estimate tropical convective and stratiform rainfall," Journal of Applied Meteorology, vol. 27, no. 1, pp. 30-51, 1988.

[70] A. J. Negri, L. Xu, and R. F. Adler, "A TRMM-calibrated infrared rainfall algorithm applied over Brazil," Journal of Geophysical Research, vol. 107, no. D20, p. 15, 2002. 
[71] C.-D. Cheng, S.-J. Cheng, J.-C. When, and J.-H. Lee, "Effects of raingauge distribution on estimation accuracy of areal rainfall," Water Resources Management, vol. 26, no. 1, pp. 1-20, 2012.

[72] S.-J. Cheng, "Rain gauge significance evaluation based on mean,” Natural Hazards, vol. 56, no. 3, pp. 767-784, 2011.

[73] F. Porcù, L. Milani, and M. Petracca, "On the uncertainties in validating satellite instantaneous rainfall estimates with operational network," Atmospheric Research, vol. 144, pp. 73-81, 2014.

[74] R. Roca, P. Chambon, I. Jobard, P.-E. Kirstetter, M. Gosset, and J. C. Berges, "Comparing satellite and surface rainfall products over west Africa at meteorologically relevant scales during the AMMA campaign using error estimates," Journal of Applied Meteorology and Climatology, vol. 49, no. 4, pp. 715-731, 2010.

[75] A. S. Falck, V. Maggioni, J. Tomasella, D. A. Vila, and F. L. R. Diniz, "Propagation of satellite precipitation uncertainties through a distributed hydrologic model: a case study in the Tocantins-basin in Brazil," Journal of Hydrology, vol. 527, pp. 943-957, 2015.

[76] H. Ashouri, K.-L. Hsu, S. Sorooshian et al., "Daily precipitation climate data record from multisatellite observations for hydrological and climate studies," Americal Meteorological Society, vol. 96, no. 1, pp. 69-83, 2014.

[77] M. R. P. Sapiano, "An evaluation of high resolution precipitation products at low resolution," International Journal of Climatology, vol. 30, pp. 1416-1422, 2010.

[78] G. Wang, P. Zhang, L. Liang, and S. Zhang, "Evaluation of precipitation from CMORPH, GPCP-2, TRMM 3B43, GPCC, and ITPCAS with ground-based measurements in the Daba Mountains, China," PLoS One, vol. 12, no. 10, Article ID e0185147, 2017.

[79] A. J. P. Filho, "Integrating gauge, radar and satellite rainfall," in Proceedings of 2nd International Precipitation Working Group Workshop, Monterey, CA, USA, October 2004.

[80] M. Azarderakhsh, W. B. Rossow, F. Papa, H. Norouzi, and R. Khanbilvardi, "Diagnosing water variations within the Amazon basin using satellite data," Journal of Geophysical Research: Atmospheres, vol. 116, no. D24, 2011.

[81] J. C. Espinoza, J. Ronchail, F. Frappart, W. Lavado, W. Santini, and J. L. Guyot, "The major floods in the Amazonas river and tributaries (western Amazon basin) during the 1970-2012 period: a focus on the 2012 flood," Journal of Hydrometeorology, vol. 14, no. 3, pp. 1000-1008, 2013.

[82] S. Ni, J. Chen, C. R. Wilson, J. Li, X. Hu, and R. Fu, "Global terrestrial water storage changes and connections to ENSO events," Surveys in Geophysics, vol. 39, no. 1, pp. 1-22, 2018.

[83] A. L. S. Swann and C. D. Koven, "A direct estimate of the seasonal cycle of evapotranspiration over the Amazon basin," Journal of Hydrometeorology, vol. 18, no. 8, pp. 2173-2185, 2017.

[84] A. Getirana, "Extreme water deficit in Brazil detected from space," Journal of Hydrometeorology, vol. 17, no. 2, pp. 591599, 2016. 

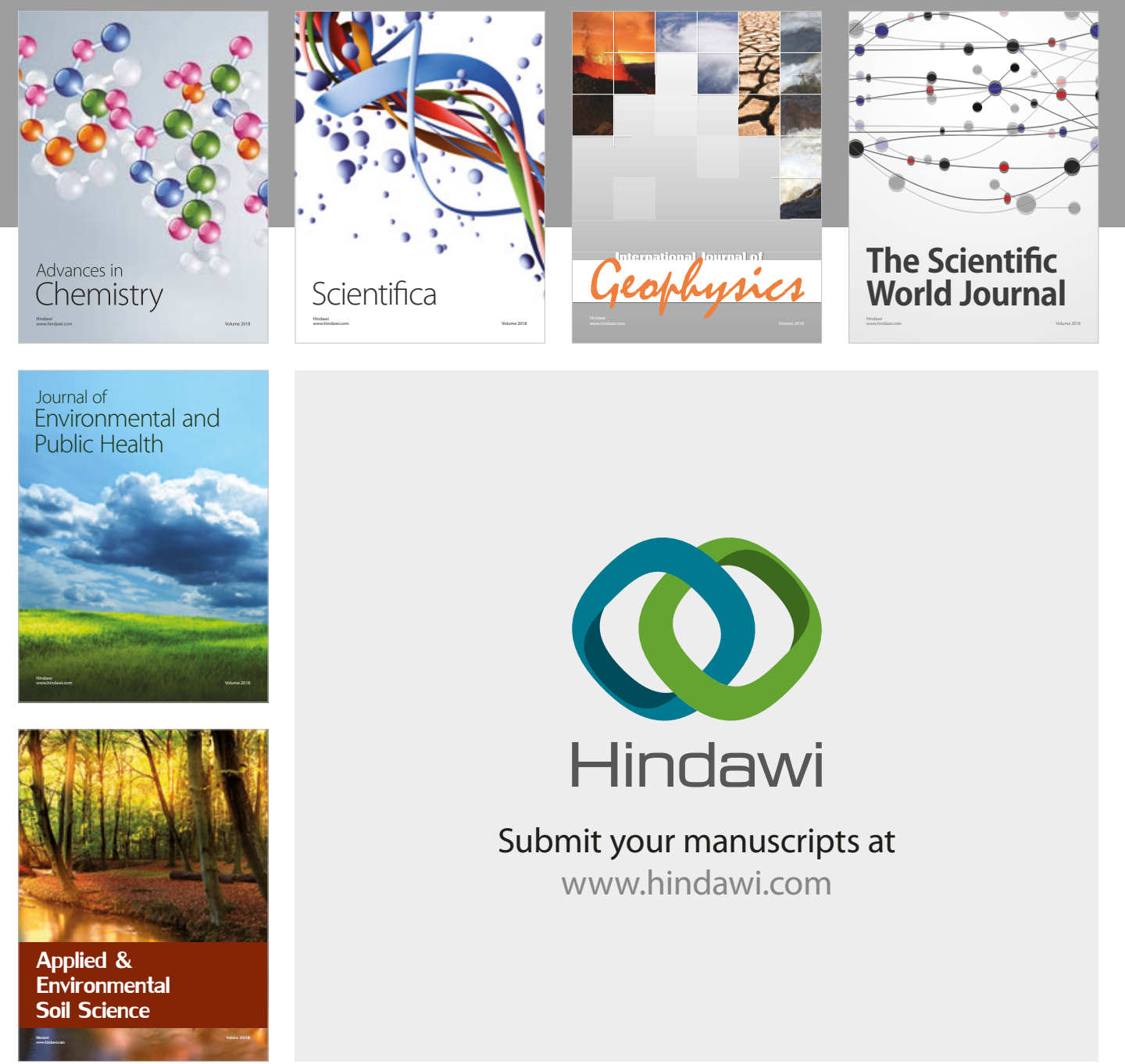

The Scientific

\section{World Journal}
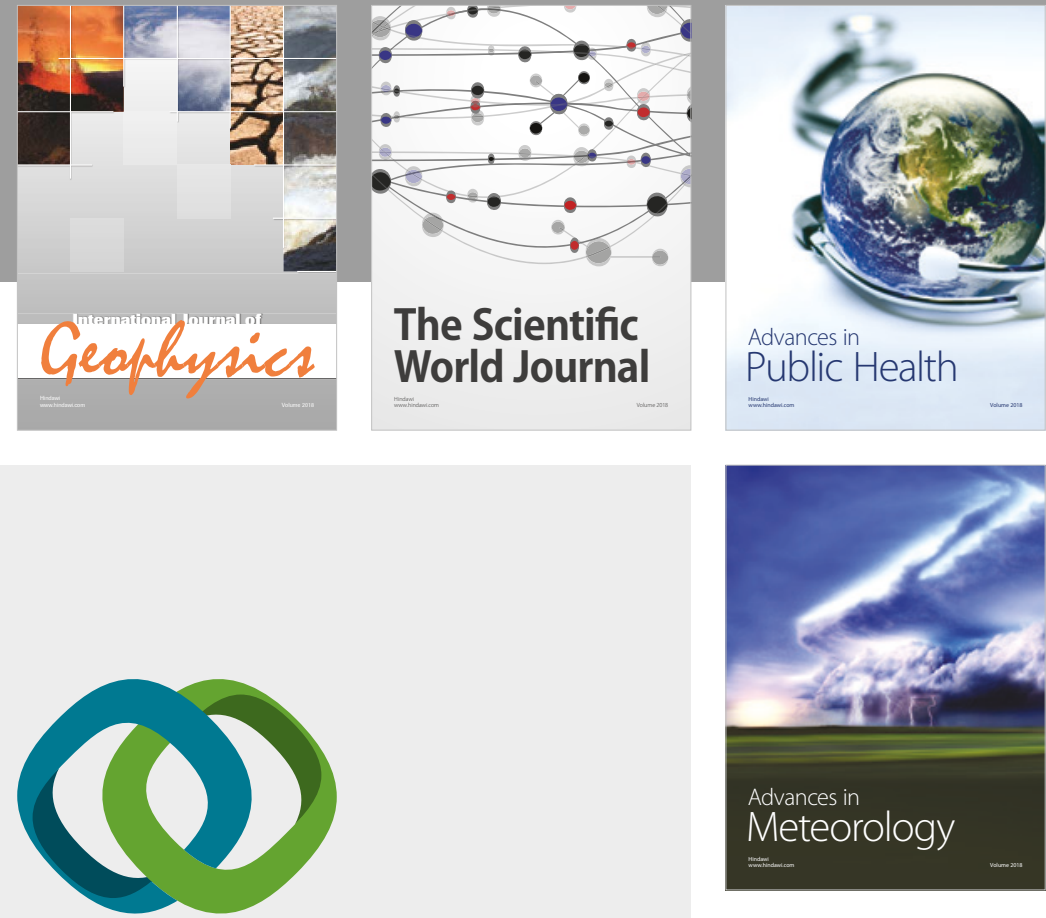

Advan

Public Health

\section{Hindawi}

Submit your manuscripts at

www.hindawi.com
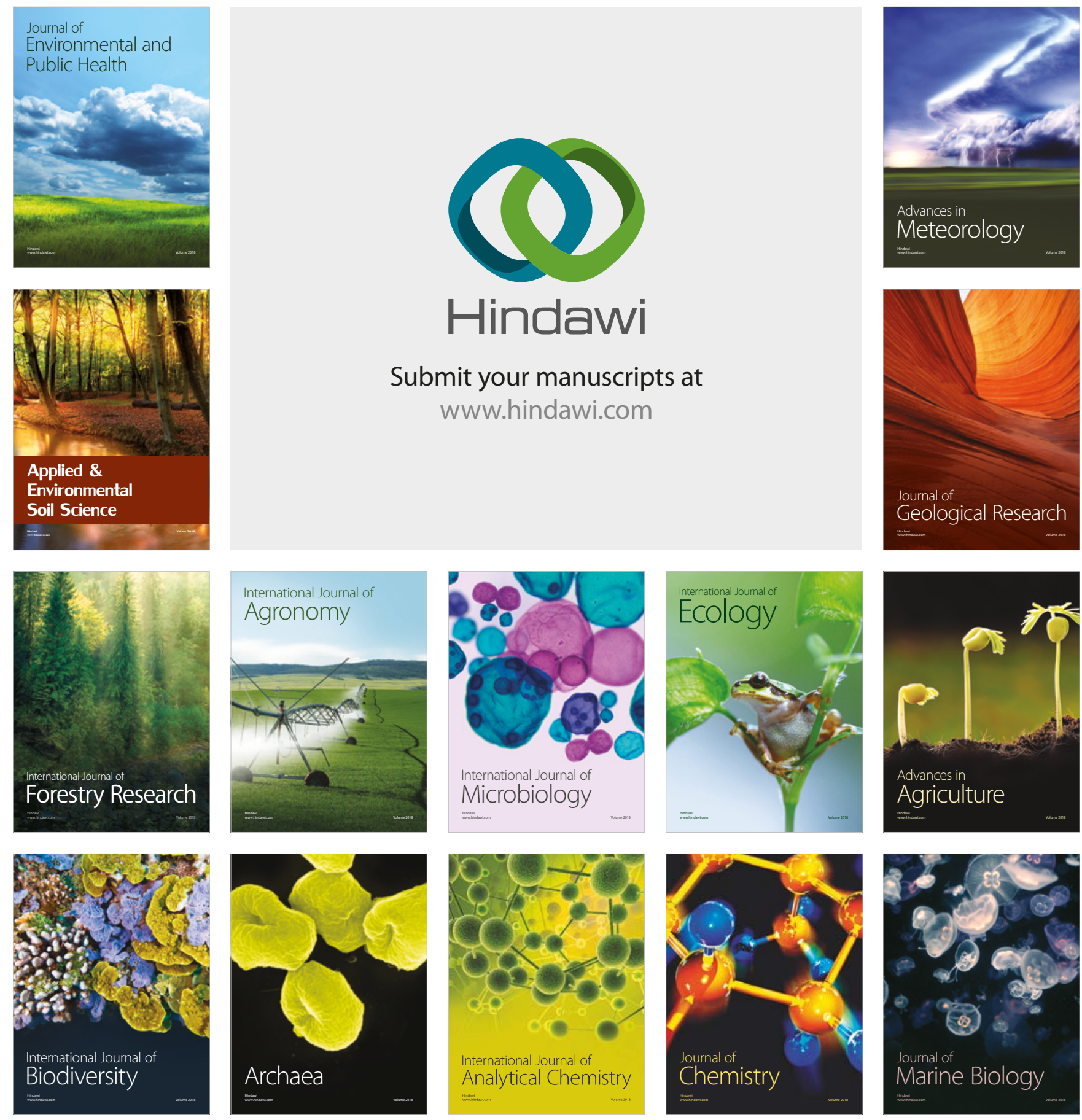